Electronic Supporting Information Materials

\title{
High in vitro and in vivo tumor-selective novel ruthenium(II)
} complexes with 3-(2'-benzimidazolyl)-7-fluoro-coumarin

Qi-Pin Qin ${ }^{a, *}$, Zhen-Feng Wang a , Xiao-Ling Huang a , Ming-Xiong Tan ${ }^{\text {a, }}{ }^{*}$, Bei-Bei Shi a and Hong Liang b,*

a Guangxi Key Lab of Agricultural Resources Chemistry and Biotechnology, College of Chemistry and Food Science, Yulin Normal University, 1303 Jiaoyudong Road, Yulin 537000, PR China. qpqin2018@126.com (Q.-P. Qin); mxtan2018@126.com (M.-X. Tan). Tel./Fax.: $+86-775-2623650$.

b State Key Laboratory for the Chemistry and Molecular Engineering of Medicinal Resources, School of Chemistry and Pharmacy, Guangxi Normal University, 15 Yucai Road, Guilin 541004, PR China. hliang@gxnu.edu.cn (H. Liang).

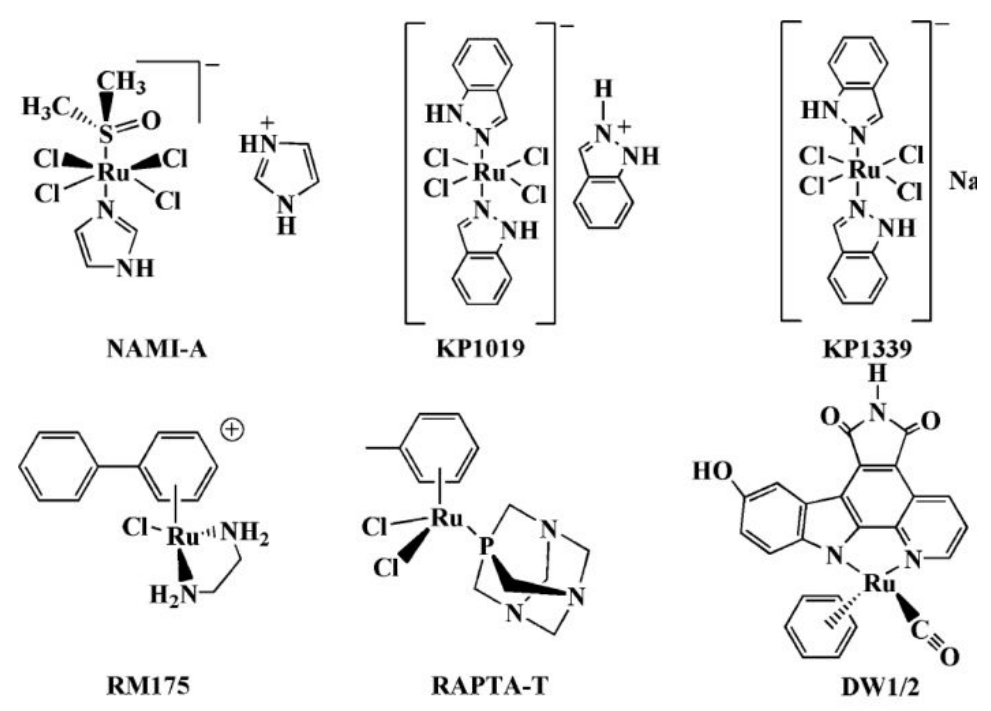

Figure S1. Examples of anti-cancer Ru(II) complexes. 
<smiles>[R]c1ccc(C=O)c(O)c1</smiles>

$\mathbf{L}^{\mathbf{a}}: \mathbf{R}=\mathbf{H}$

Ru1: $\mathbf{R}=\mathbf{H}$;

$\mathbf{L}^{\mathrm{b}}: \mathbf{R}=\mathbf{F}$;

Ru2: $\mathbf{R}=\mathbf{F}$;

$L^{\mathrm{c}}: \mathbf{R}=\mathrm{CH}_{3} \mathrm{O}$.

Ru3: $\mathrm{R}=\mathrm{CH}_{3} \mathrm{O}$.

Scheme S1. Synthetic routes for $\left[\mathrm{RuCl}_{2}\left(\mathrm{~L}^{\mathrm{a}}\right)(\mathrm{DMSO})_{2}\right] \cdot \mathrm{H}_{2} \mathrm{O}$ (Ru1), $\left[\mathrm{RuCl}_{2}\left(\mathrm{~L}^{\mathrm{b}}\right)(\mathrm{DMSO})_{2}\right](\mathbf{R u} 2)$ and $\left[\mathrm{RuCl}_{2}\left(\mathrm{~L}^{\mathrm{c}}\right)(\mathrm{DMSO})_{2}\right]$ (Ru3). (a) piperidine $(0.1 \mathrm{~mL})$, $\mathrm{CH}_{3} \mathrm{CH}_{2} \mathrm{OH} \quad(50.0 \mathrm{~mL}), \quad 37^{\circ} \mathrm{C}, \quad 6.0 \quad \mathrm{~h} ; \quad$ (b) $2.0 \quad \% \quad \mathrm{HCl} \quad(250.0 \mathrm{~mL}) ; \quad$ (c) cis- $\mathrm{RuCl}_{2}(\mathrm{DMSO})_{4}, \mathrm{CH}_{3} \mathrm{OH} / \mathrm{CH}_{2} \mathrm{Cl}_{2}(5: 2), 60^{\circ} \mathrm{C}, 12.0 \mathrm{~h}$.

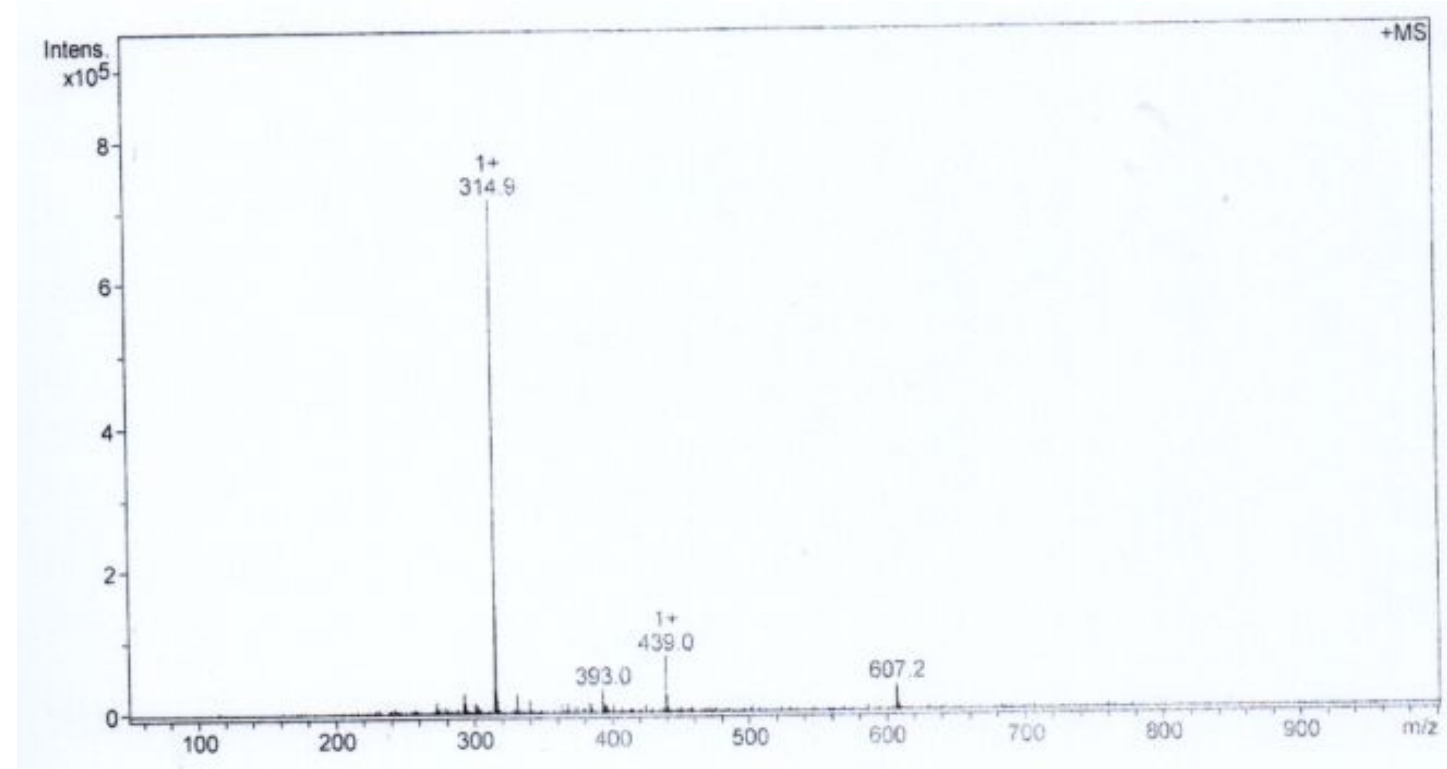

Figure S2. The mass spectra of $\mathrm{L}^{\mathrm{c}}$ in Tris- $\mathrm{HCl}$ buffer solution (containing 5\% DMSO) for $0 \mathrm{~h}$. 


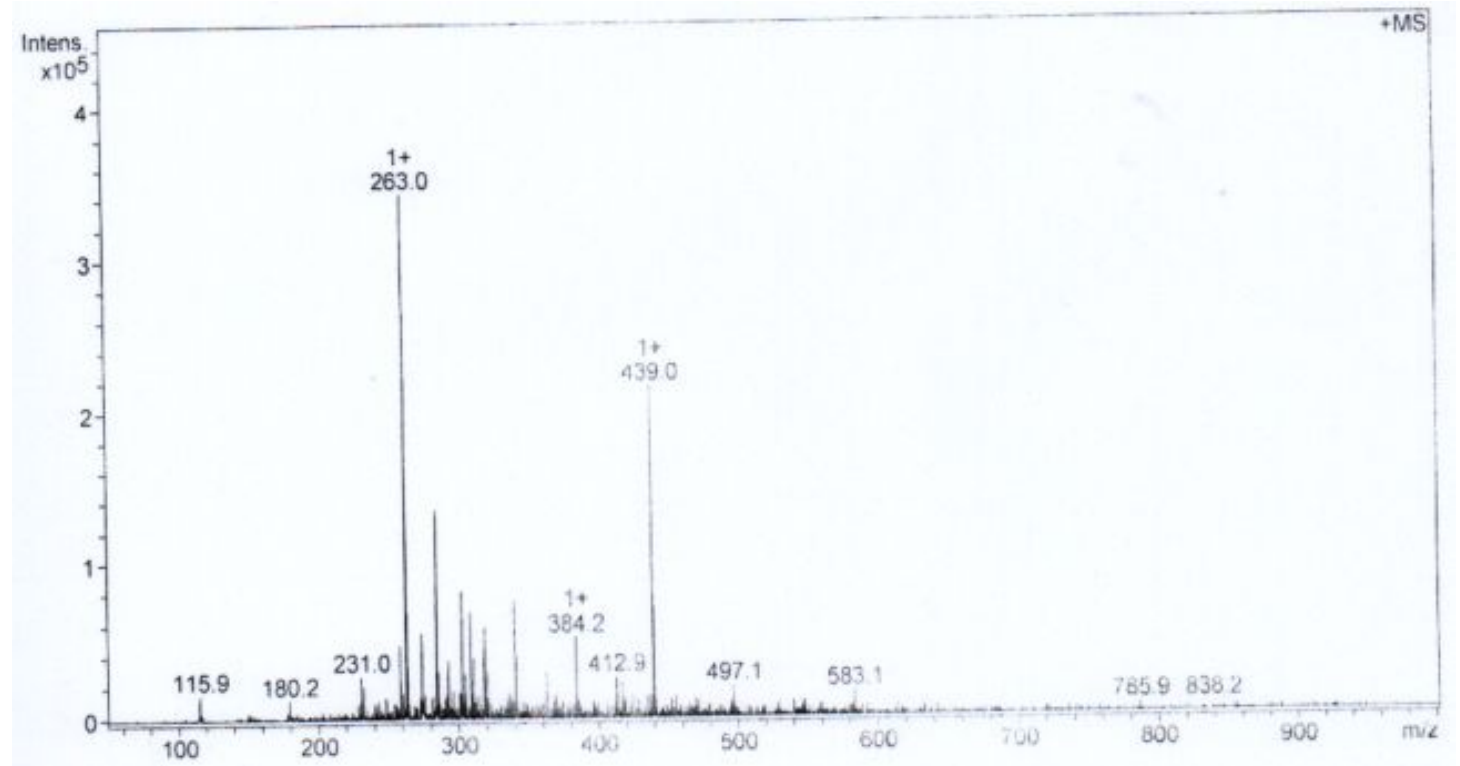

Figure S3. The mass spectra of $\mathrm{L}^{\mathrm{a}}$ in Tris- $\mathrm{HCl}$ buffer solution (containing 5\% DMSO) for $0 \mathrm{~h}$.

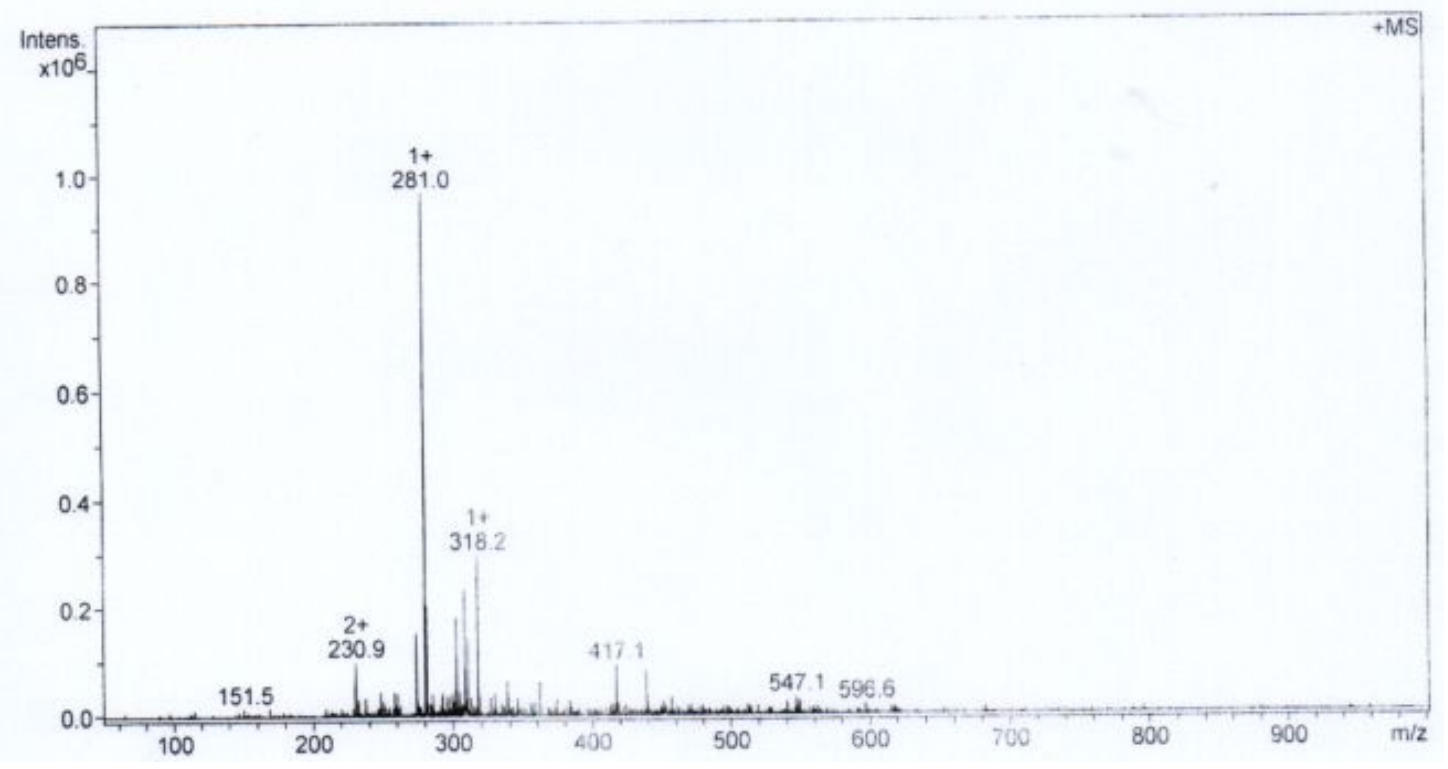

Figure S4. The mass spectra of $\mathrm{L}^{\mathrm{b}}$ in Tris- $\mathrm{HCl}$ buffer solution (containing 5\% DMSO) for $0 \mathrm{~h}$. 


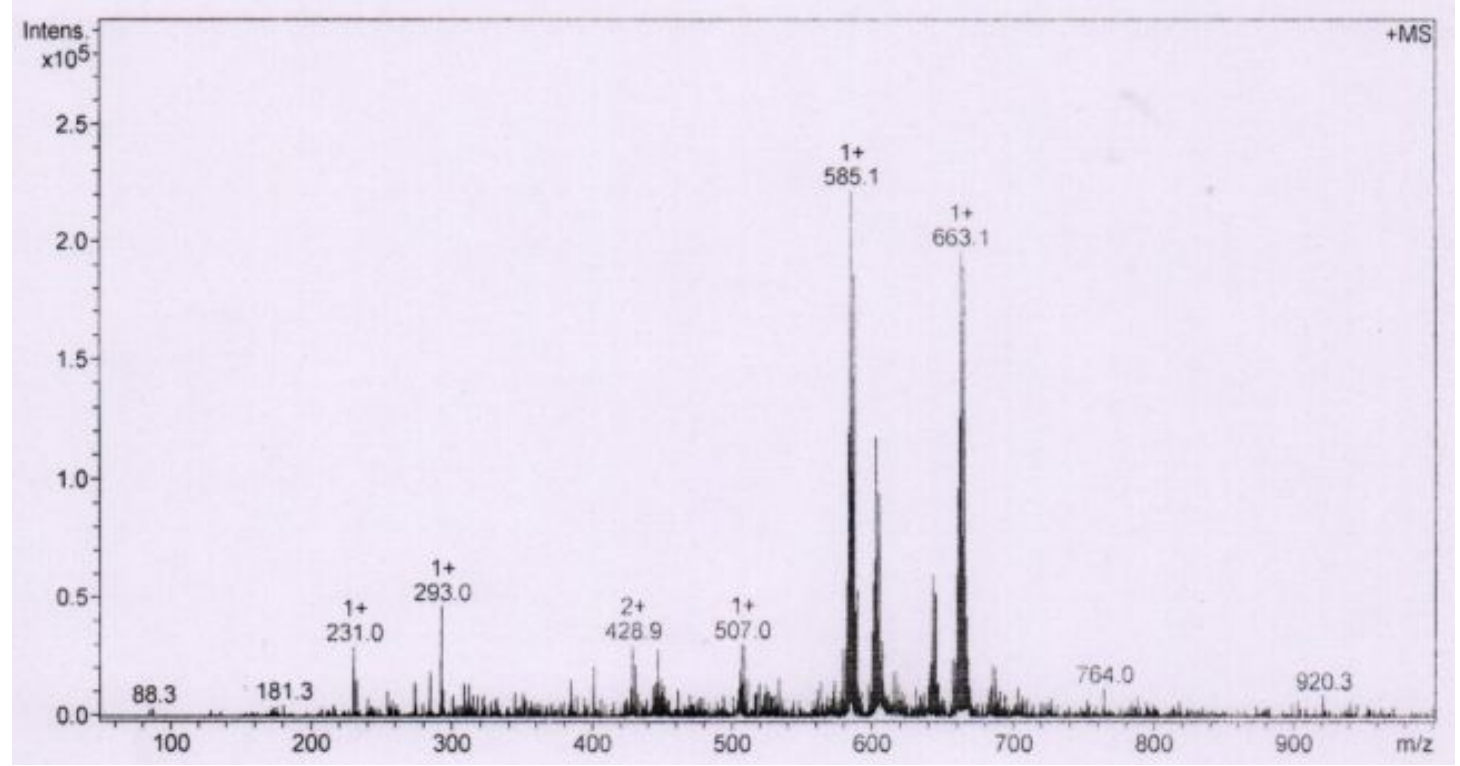

Figure S5. The mass spectra of Ru3 in Tris- $\mathrm{HCl}$ buffer solution (containing 5\% DMSO) for $0 \mathrm{~h}$.

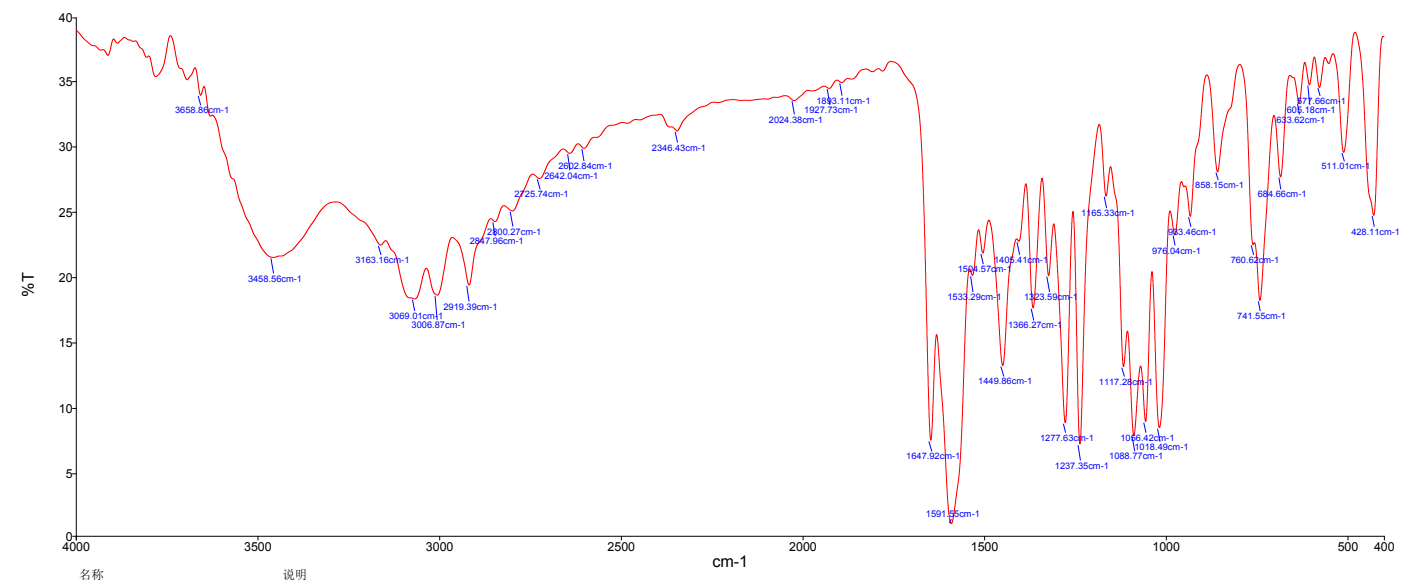

Figure S6. IR (KBr) spectra of Ru3 


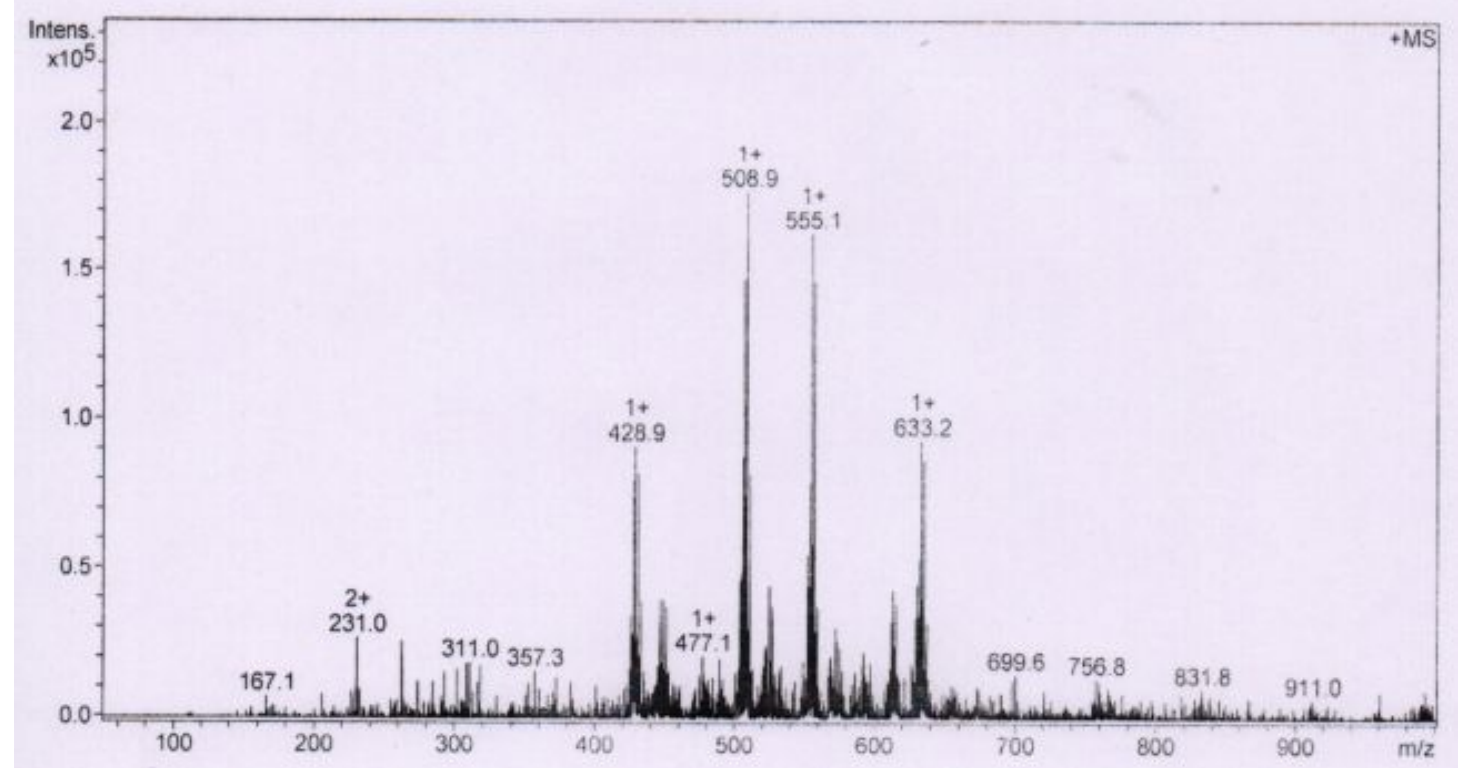

Figure S7. The mass spectra of Ru1 in Tris- $\mathrm{HCl}$ buffer solution (containing 5\% DMSO) for $0 \mathrm{~h}$.

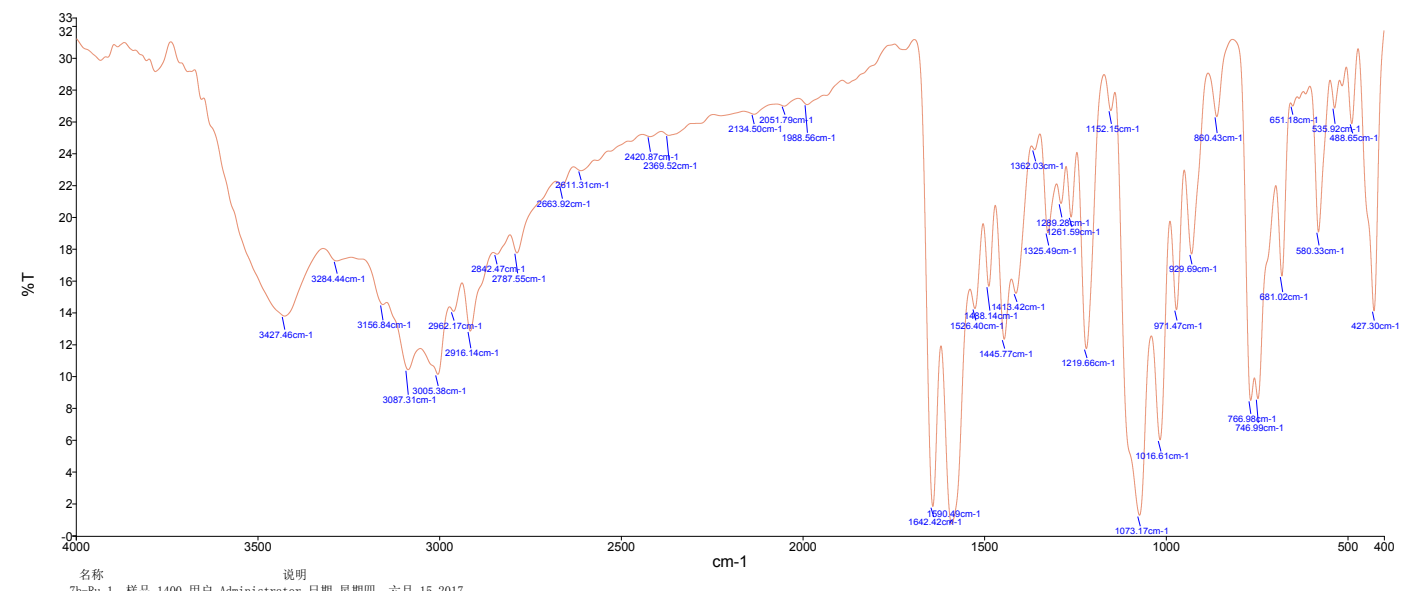

Figure S8. IR (KBr) spectra of Ru1 


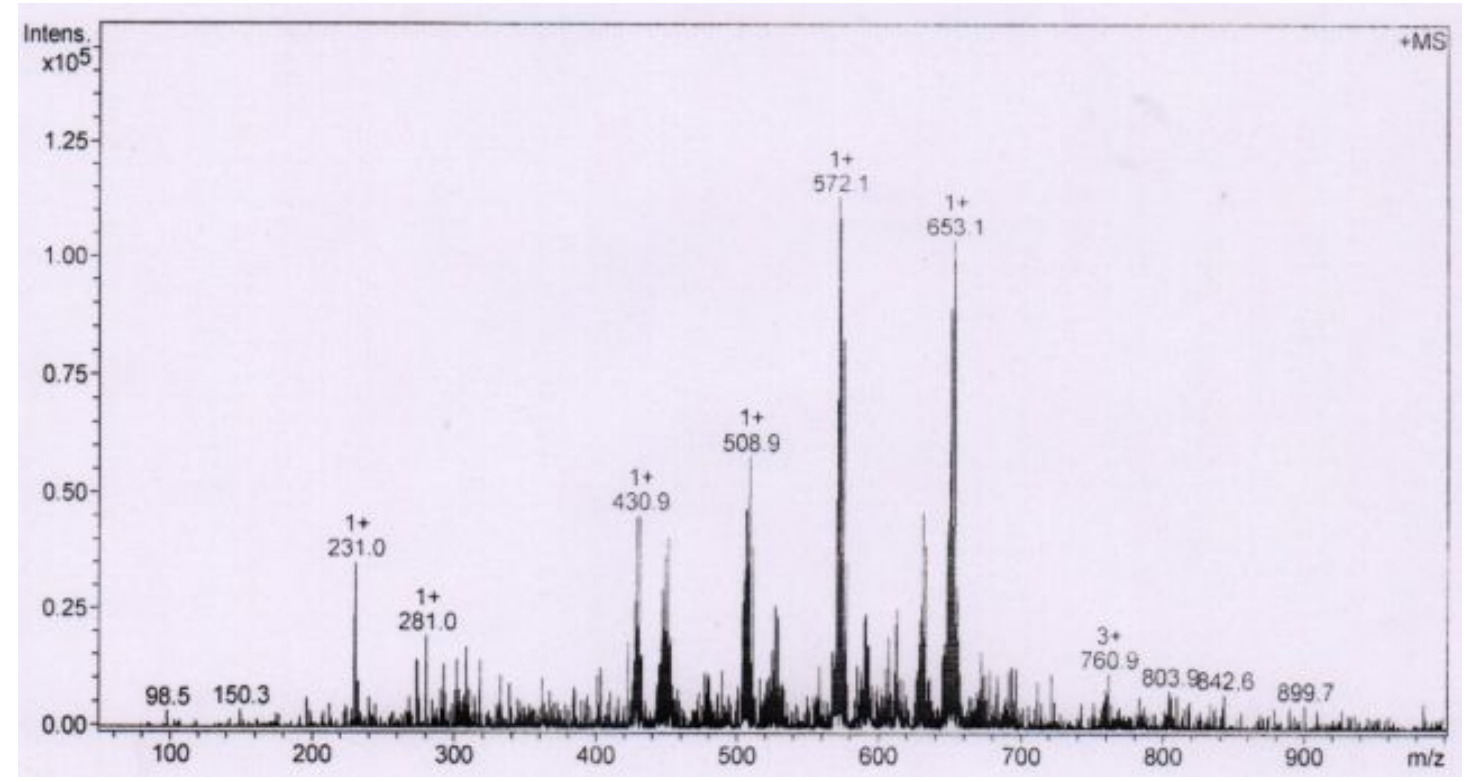

Figure S9. The mass spectra of Ru2 in Tris- $\mathrm{HCl}$ buffer solution (containing 5\% DMSO) for $0 \mathrm{~h}$.

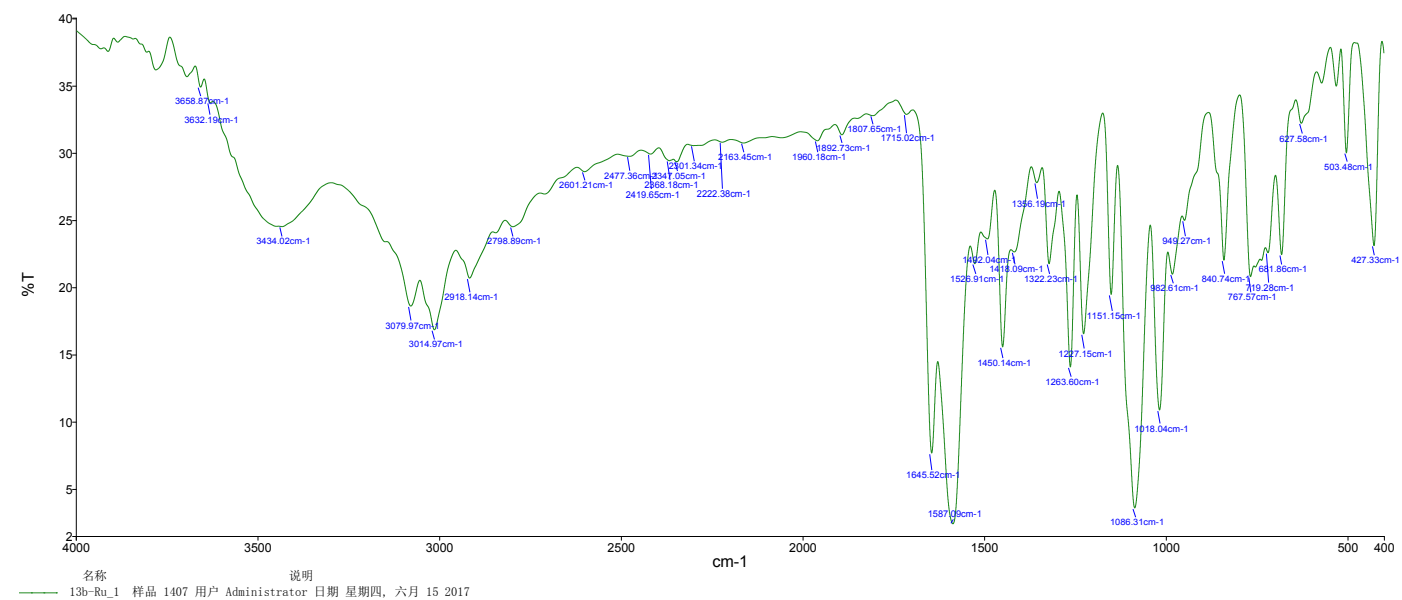

Figure S10. IR (KBr) spectra of Ru2

Table S1. Crystal data and structure refinement details for Ru1.

\begin{tabular}{ll}
\hline Empirical formula & $\mathrm{C}_{20} \mathrm{H}_{24} \mathrm{Cl}_{2} \mathrm{~N}_{2} \mathrm{O}_{5} \mathrm{RuS}_{2}$ \\
Formula weight & 608.50 \\
Temperature/K & $293(2)$ \\
Crystal system & monoclinic \\
Space group & $\mathrm{P} 2{ }_{1} / \mathrm{n}$ \\
$\mathrm{a} / \AA$ & $13.5791(4)$ \\
$\mathrm{b} / \AA$ & $13.2566(3)$ \\
$\mathrm{c} / \AA$ & $14.8366(5)$ \\
$\alpha /{ }^{\circ}$ & 90 \\
\hline
\end{tabular}




\begin{tabular}{ll}
\hline$\beta /{ }^{\circ}$ & $115.267(4)$ \\
$\gamma /{ }^{\circ}$ & 90 \\
Volume $/ \AA^{3}$ & $2415.24(14)$ \\
$\mathrm{Z}$ & 4 \\
$\rho_{\text {calc }} / \mathrm{cm}^{3}$ & 1.673 \\
$\mu / \mathrm{mm}^{-1}$ & 1.078 \\
$\mathrm{~F}(000)$ & 1232.0 \\
$\mathrm{Crystal}$ size $/ \mathrm{mm}^{3}$ & $0.28 \times 0.14 \times 0.16$ \\
Radiation & $\mathrm{MoK} \alpha(\lambda=0.71073)$ \\
$2 \Theta$ range for data collection $/{ }^{\circ} 6.636$ to 52.744 \\
Index ranges & $-16 \leq \mathrm{h} \leq 16,-15 \leq \mathrm{k} \leq 16,-18 \leq 1 \leq 17$ \\
Reflections collected & 15776 \\
Independent reflections & $4908\left[\mathrm{R}_{\text {int }}=0.0329, \mathrm{R}_{\text {sigma }}=0.0376\right]$ \\
Data/restraints/parameters & $4908 / 0 / 293$ \\
Goodness-of-fit on $\mathrm{F}^{2}$ & 1.046 \\
Final R indexes $[\mathrm{I}>=2 \sigma(\mathrm{I})]$ & $\mathrm{R}_{1}=0.0371, \mathrm{wR}_{2}=0.0874$ \\
Final R indexes [all data] & $\mathrm{R}_{1}=0.0492, \mathrm{wR}_{2}=0.0951$ \\
Largest diff. peak/hole / e $\AA^{-3} 1.64 /-1.45$ \\
\hline
\end{tabular}

${ }^{\mathrm{a}} R_{1}=\Sigma|| F_{\mathrm{o}}|-| F_{\mathrm{c}}|| \Sigma\left|F_{\mathrm{o}}\right| ;{ }^{\mathrm{b}} w R_{2}=\left[\Sigma w\left(F_{\mathrm{o}}{ }^{2}-F_{\mathrm{c}}{ }^{2}\right)^{2} / \Sigma w\left(F_{\mathrm{o}}{ }^{2}\right)^{2}\right]^{1 / 2}$

Table S2. Selected bond lengths $(\AA)$ for Ru1.

\begin{tabular}{|c|c|c|c|c|c|}
\hline \multicolumn{2}{|c|}{ Atom Atom } & \multirow{2}{*}{$\begin{array}{c}\text { Length/ } \AA \\
2.2302(9)\end{array}$} & \multicolumn{2}{|c|}{ Atom Atom } & \multirow{2}{*}{$\frac{\text { Length/Å }}{1.358(4)}$} \\
\hline Rul & $\mathrm{S} 2$ & & N2 & $\mathrm{C} 10$ & \\
\hline Rul & S1 & $2.2542(9)$ & $\mathrm{C} 15$ & $\mathrm{C} 16$ & $1.387(5)$ \\
\hline Rul & $\mathrm{Cl1}$ & $2.4341(10)$ & $\mathrm{C} 15$ & $\mathrm{C} 14$ & $1.378(6)$ \\
\hline Rul & $\mathrm{C} 12$ & $2.3885(10)$ & $\mathrm{C} 16$ & $\mathrm{C} 11$ & $1.400(5)$ \\
\hline $\mathrm{Rul}$ & $\mathrm{O} 1$ & $2.117(2)$ & C6 & $\mathrm{C} 7$ & $1.399(5)$ \\
\hline Rul & N1 & $2.121(3)$ & C6 & $\mathrm{C} 5$ & $1.368(6)$ \\
\hline $\mathrm{S} 2$ & $\mathrm{O} 4$ & $1.482(3)$ & $\mathrm{C} 8$ & $\mathrm{C} 9$ & $1.353(5)$ \\
\hline $\mathrm{S} 2$ & $\mathrm{C} 21$ & $1.774(4)$ & $\mathrm{C} 8$ & $\mathrm{C} 7$ & $1.419(5)$ \\
\hline $\mathrm{S} 2$ & $\mathrm{C} 20$ & $1.773(4)$ & $\mathrm{C} 11$ & $\mathrm{C} 12$ & $1.384(5)$ \\
\hline $\mathrm{S} 1$ & $\mathrm{O} 3$ & $1.483(3)$ & C9 & $\mathrm{C} 1$ & $1.443(5)$ \\
\hline $\mathrm{S} 1$ & $\mathrm{C} 17$ & $1.785(4)$ & C9 & $\mathrm{C} 10$ & $1.463(5)$ \\
\hline $\mathrm{S} 1$ & C19 & $1.777(5)$ & $\mathrm{C} 12$ & $\mathrm{C} 13$ & $1.376(6)$ \\
\hline $\mathrm{O} 1$ & $\mathrm{C} 1$ & $1.236(4)$ & $\mathrm{C} 7$ & $\mathrm{C} 2$ & $1.385(6)$ \\
\hline $\mathrm{O} 2$ & $\mathrm{C} 1$ & $1.344(4)$ & $\mathrm{C} 4$ & $\mathrm{C} 3$ & $1.376(7)$ \\
\hline $\mathrm{O} 2$ & $\mathrm{C} 2$ & $1.380(5)$ & $\mathrm{C} 4$ & $\mathrm{C} 5$ & $1.385(7)$ \\
\hline N1 & $\mathrm{C} 16$ & $1.397(4)$ & $\mathrm{C} 2$ & $\mathrm{C} 3$ & $1.386(6)$ \\
\hline N1 & $\mathrm{C} 10$ & $1.323(5)$ & $\mathrm{C} 14$ & $\mathrm{C} 13$ & $1.387(6)$ \\
\hline $\mathrm{N} 2$ & $\mathrm{C} 11$ & $1.373(5)$ & & & \\
\hline
\end{tabular}


Table S3. Selected bond angles $\left(^{\circ}\right)$ for Ru1.

\begin{tabular}{|c|c|c|c|c|c|c|c|}
\hline \multicolumn{3}{|c|}{ Atom Atom Atom } & \multirow{2}{*}{$\frac{\text { Angle/ }^{\circ}}{93.55(4)}$} & \multicolumn{3}{|c|}{ Atom Atom Atom } & \multirow{2}{*}{$\frac{\text { Angle }^{\circ}}{107.9(3)}$} \\
\hline S2 & Rul & S1 & & $\mathrm{C} 10$ & $\mathrm{~N} 2$ & $\mathrm{C} 11$ & \\
\hline $\mathrm{S} 2$ & Rul & $\mathrm{C} 11$ & $172.37(4)$ & $\mathrm{C} 14$ & $\mathrm{C} 15$ & $\mathrm{C} 16$ & $117.8(4)$ \\
\hline S2 & Rul & $\mathrm{C} 12$ & $95.71(4)$ & N1 & $\mathrm{C} 16$ & $\mathrm{C} 11$ & $108.6(3)$ \\
\hline S1 & Rul & $\mathrm{C} 11$ & $90.81(3)$ & $\mathrm{C} 15$ & $\mathrm{C} 16$ & N1 & $131.4(4)$ \\
\hline S1 & Rul & $\mathrm{C} 12$ & $86.75(4)$ & $\mathrm{C} 15$ & $\mathrm{C} 16$ & $\mathrm{C} 11$ & $120.0(3)$ \\
\hline $\mathrm{Cl} 2$ & Ru1 & $\mathrm{Cl1}$ & $90.79(4)$ & $\mathrm{C} 5$ & C6 & $\mathrm{C} 7$ & $119.6(4)$ \\
\hline $\mathrm{O} 1$ & Rul & S2 & $89.80(8)$ & C9 & $\mathrm{C} 8$ & $\mathrm{C} 7$ & $121.7(3)$ \\
\hline $\mathrm{O} 1$ & Rul & S1 & $91.24(7)$ & N2 & $\mathrm{C} 11$ & $\mathrm{C} 16$ & $105.8(3)$ \\
\hline $\mathrm{O} 1$ & Ru1 & $\mathrm{C} 11$ & $83.83(7)$ & $\mathrm{N} 2$ & $\mathrm{C} 11$ & $\mathrm{C} 12$ & $131.8(4)$ \\
\hline $\mathrm{O} 1$ & Rul & $\mathrm{C} 12$ & $174.24(8)$ & $\mathrm{C} 12$ & $\mathrm{C} 11$ & $\mathrm{C} 16$ & $122.4(4)$ \\
\hline $\mathrm{O} 1$ & Rul & N1 & $86.06(10)$ & $\mathrm{C} 8$ & C9 & $\mathrm{C} 1$ & 119.1(3) \\
\hline N1 & Rul & $\mathrm{S} 2$ & $87.76(8)$ & $\mathrm{C} 8$ & C9 & $\mathrm{C} 10$ & $122.0(3)$ \\
\hline N1 & Rul & S1 & $177.00(8)$ & $\mathrm{C} 1$ & C9 & $\mathrm{C} 10$ & $118.7(3)$ \\
\hline N1 & Rul & $\mathrm{C} 11$ & $87.60(8)$ & $\mathrm{O} 1$ & $\mathrm{C} 1$ & $\mathrm{O} 2$ & $114.3(3)$ \\
\hline N1 & Rul & $\mathrm{C} 12$ & $95.81(8)$ & $\mathrm{O} 1$ & $\mathrm{C} 1$ & C9 & $127.0(3)$ \\
\hline $\mathrm{O} 4$ & $\mathrm{~S} 2$ & Ru1 & $114.85(12)$ & $\mathrm{O} 2$ & $\mathrm{C} 1$ & C9 & $118.7(3)$ \\
\hline $\mathrm{O} 4$ & $\mathrm{~S} 2$ & $\mathrm{C} 21$ & $104.0(2)$ & N1 & $\mathrm{C} 10$ & $\mathrm{~N} 2$ & $111.8(3)$ \\
\hline $\mathrm{O} 4$ & $\mathrm{~S} 2$ & $\mathrm{C} 20$ & $105.9(2)$ & N1 & $\mathrm{C} 10$ & $\mathrm{C} 9$ & $128.1(3)$ \\
\hline $\mathrm{C} 21$ & S2 & Ru1 & $113.23(16)$ & N2 & $\mathrm{C} 10$ & C9 & $120.1(3)$ \\
\hline $\mathrm{C} 20$ & $\mathrm{~S} 2$ & Ru1 & $116.69(16)$ & $\mathrm{C} 13$ & $\mathrm{C} 12$ & C11 & $116.3(4)$ \\
\hline $\mathrm{C} 20$ & $\mathrm{~S} 2$ & $\mathrm{C} 21$ & $100.4(3)$ & C6 & $\mathrm{C} 7$ & $\mathrm{C} 8$ & $123.9(4)$ \\
\hline $\mathrm{O} 3$ & S1 & Ru1 & $119.12(12)$ & $\mathrm{C} 2$ & $\mathrm{C} 7$ & C6 & $118.4(4)$ \\
\hline $\mathrm{O} 3$ & S1 & $\mathrm{C} 17$ & $105.1(2)$ & $\mathrm{C} 2$ & $\mathrm{C} 7$ & $\mathrm{C} 8$ & $117.6(3)$ \\
\hline $\mathrm{O} 3$ & $\mathrm{~S} 1$ & C19 & $106.5(2)$ & $\mathrm{C} 3$ & $\mathrm{C} 4$ & C5 & $121.1(4)$ \\
\hline $\mathrm{C} 17$ & S1 & Ru1 & $113.52(16)$ & $\mathrm{O} 2$ & $\mathrm{C} 2$ & $\mathrm{C} 7$ & $120.6(3)$ \\
\hline C19 & $\mathrm{S} 1$ & Ru1 & $110.54(15)$ & $\mathrm{O} 2$ & $\mathrm{C} 2$ & $\mathrm{C} 3$ & $117.0(4)$ \\
\hline $\mathrm{C} 19$ & $\mathrm{~S} 1$ & $\mathrm{C} 17$ & $100.2(3)$ & $\mathrm{C} 7$ & $\mathrm{C} 2$ & $\mathrm{C} 3$ & $122.4(4)$ \\
\hline $\mathrm{C} 1$ & $\mathrm{O} 1$ & Ru1 & $122.4(2)$ & C15 & $\mathrm{C} 14$ & $\mathrm{C} 13$ & $121.3(4)$ \\
\hline $\mathrm{C} 1$ & $\mathrm{O} 2$ & $\mathrm{C} 2$ & $122.1(3)$ & $\mathrm{C} 12$ & $\mathrm{C} 13$ & $\mathrm{C} 14$ & $122.2(4)$ \\
\hline $\mathrm{C} 16$ & N1 & Ru1 & $131.2(2)$ & $\mathrm{C} 4$ & $\mathrm{C} 3$ & $\mathrm{C} 2$ & $117.7(5)$ \\
\hline $\mathrm{C} 10$ & N1 & Ru1 & $122.2(2)$ & C6 & $\mathrm{C} 5$ & $\mathrm{C} 4$ & $120.8(4)$ \\
\hline $\mathrm{C} 10$ & N1 & $\mathrm{C} 16$ & $106.0(3)$ & & & & \\
\hline
\end{tabular}

Table S4. Crystal data and structure refinement details for Ru2.

\begin{tabular}{ll}
\hline Empirical formula & $\mathrm{C}_{20} \mathrm{H}_{21} \mathrm{Cl}_{2} \mathrm{FN}_{2} \mathrm{O}_{4} \mathrm{RuS}_{2}$ \\
Formula weight & 608.48 \\
Temperature/K & $293(2)$ \\
Crystal system & monoclinic \\
\hline
\end{tabular}




\begin{tabular}{ll}
\hline Space group & $\mathrm{P}{ }_{1} / \mathrm{c}$ \\
$\mathrm{a} / \AA$ & $8.5531(12)$ \\
$\mathrm{b} / \AA$ & $11.530(2)$ \\
$\mathrm{c} / \AA$ & $23.621(4)$ \\
$\alpha /^{\circ}$ & 90 \\
$\beta /{ }^{\circ}$ & $94.049(13)$ \\
$\gamma^{\circ}$ & 90 \\
$\mathrm{~V}^{\circ}$ & $2323.5(7)$ \\
$\mathrm{Z}$ & 4 \\
$\rho_{\text {calcg }} / \mathrm{cm}^{3}$ & 1.739 \\
$\mu / \mathrm{mm}^{-1}$ & 1.123 \\
$\mathrm{~F}(000)$ & 1224.0 \\
$\mathrm{Crystal}$ size/mm & \\
Radiation & $0.25 \times 0.19 \times 0.15$ \\
$2 \Theta$ range for data collection $/{ }^{\circ} 6.702$ to 52.74 \\
Index ranges & $-10 \leq \mathrm{h} \leq 10,-12 \leq \mathrm{k} \leq 14,-29 \leq 1 \leq 28$ \\
Reflections collected & 15189 \\
Independent reflections & $4738\left[\mathrm{R}_{\text {int }}=0.0302, \mathrm{R}_{\text {sigma }}=0.0304\right]$ \\
Data/restraints/parameters & $4738 / 0 / 293$ \\
Goodness-of-fit on $\mathrm{F}^{2}$ & 1.058 \\
Final $\mathrm{R}$ indexes $[\mathrm{I}>=2 \sigma(\mathrm{I})]$ & $\mathrm{R}_{1}=0.0412, \mathrm{wR}_{2}=0.0944$ \\
Final R indexes [all data] & $\mathrm{R}_{1}=0.0485, \mathrm{wR}_{2}=0.0979$ \\
Largest diff. peak/hole / e $\AA^{-3} 1.79 /-0.64$ \\
\hline
\end{tabular}

Table S5. Selected bond lengths $(\AA)$ for Ru2.

\begin{tabular}{|c|c|c|c|c|c|}
\hline \multicolumn{2}{|c|}{ Atom Atom } & \multirow{2}{*}{$\frac{\text { Length/§ }}{2.2275(11)}$} & \multicolumn{2}{|c|}{ Atom Atom } & \multirow{2}{*}{$\frac{\text { Length/Å }}{1.348(5)}$} \\
\hline Ru1 & S1 & & N2 & $\mathrm{C} 10$ & \\
\hline Rul & $\mathrm{Cl1}$ & $2.3801(12)$ & $\mathrm{N} 2$ & $\mathrm{C} 11$ & $1.368(5)$ \\
\hline Rul & $\mathrm{Cl} 2$ & $2.4255(11)$ & $\mathrm{C} 10$ & C9 & $1.456(5)$ \\
\hline Rul & $\mathrm{S} 2$ & $2.2456(12)$ & $\mathrm{C} 11$ & $\mathrm{C} 16$ & $1.409(5)$ \\
\hline Rul & $\mathrm{O} 1$ & $2.118(3)$ & $\mathrm{C} 11$ & $\mathrm{C} 12$ & $1.387(5)$ \\
\hline $\mathrm{Ru} 1$ & N1 & $2.116(3)$ & $\mathrm{C} 7$ & $\mathrm{C} 8$ & $1.419(6)$ \\
\hline S1 & $\mathrm{O} 3$ & $1.435(3)$ & $\mathrm{C} 7$ & $\mathrm{C} 2$ & $1.395(6)$ \\
\hline $\mathrm{S} 1$ & $\mathrm{C} 17$ & $1.788(4)$ & $\mathrm{C} 7$ & C6 & $1.414(6)$ \\
\hline $\mathrm{S} 1$ & $\mathrm{C} 18$ & $1.795(5)$ & $\mathrm{C} 4$ & $\mathrm{C} 5$ & $1.385(8)$ \\
\hline S2 & $\mathrm{O} 4$ & $1.495(3)$ & $\mathrm{C} 4$ & $\mathrm{C} 3$ & $1.385(7)$ \\
\hline $\mathrm{S} 2$ & $\mathrm{C} 20$ & $1.760(5)$ & $\mathrm{C} 8$ & C9 & $1.365(5)$ \\
\hline $\mathrm{S} 2$ & C19 & $1.794(5)$ & C9 & $\mathrm{C} 1$ & $1.452(5)$ \\
\hline $\mathrm{F} 1$ & $\mathrm{C} 4$ & $1.339(5)$ & $\mathrm{C} 16$ & $\mathrm{C} 15$ & $1.392(5)$ \\
\hline $\mathrm{O} 1$ & $\mathrm{C} 1$ & $1.247(5)$ & $\mathrm{C} 13$ & $\mathrm{C} 14$ & $1.396(6)$ \\
\hline $\mathrm{O} 2$ & $\mathrm{C} 1$ & $1.347(4)$ & $\mathrm{C} 13$ & $\mathrm{C} 12$ & $1.361(6)$ \\
\hline $\mathrm{O} 2$ & $\mathrm{C} 2$ & $1.388(5)$ & $\mathrm{C} 14$ & $\mathrm{C} 15$ & $1.368(6)$ \\
\hline N1 & $\mathrm{C} 10$ & $1.333(5)$ & $\mathrm{C} 5$ & C6 & $1.373(7)$ \\
\hline N1 & $\mathrm{C} 16$ & $1.383(4)$ & $\mathrm{C} 3$ & $\mathrm{C} 2$ & $1.380(6)$ \\
\hline
\end{tabular}


Table S6. Selected bond angles $\left(^{\circ}\right)$ for Ru2.

\begin{tabular}{|c|c|c|c|c|c|c|c|}
\hline \multicolumn{3}{|c|}{ Atom Atom Atom } & \multirow{2}{*}{$\frac{\text { Angle/ }^{\circ}}{94.91(4)}$} & \multicolumn{3}{|c|}{ Atom Atom Atom } & \multirow{2}{*}{$\frac{\text { Angle }^{\circ}}{112.1(3)}$} \\
\hline $\mathrm{S} 1$ & Rul & $\mathrm{Cl1}$ & & N1 & $\mathrm{C} 10$ & N2 & \\
\hline $\mathrm{S} 1$ & Rul & $\mathrm{C} 12$ & $173.29(4)$ & N1 & $\mathrm{C} 10$ & $\mathrm{C} 9$ & $127.0(3)$ \\
\hline $\mathrm{S} 1$ & Rul & $\mathrm{S} 2$ & $92.60(4)$ & $\mathrm{N} 2$ & $\mathrm{C} 10$ & C9 & $120.9(3)$ \\
\hline $\mathrm{Cl1}$ & Ru1 & $\mathrm{Cl} 2$ & $91.46(4)$ & N2 & $\mathrm{C} 11$ & $\mathrm{C} 16$ & $106.5(3)$ \\
\hline $\mathrm{S} 2$ & Rul & $\mathrm{Cl1}$ & $85.70(4)$ & $\mathrm{N} 2$ & $\mathrm{C} 11$ & $\mathrm{C} 12$ & $131.7(4)$ \\
\hline $\mathrm{S} 2$ & Rul & $\mathrm{Cl} 2$ & $89.96(4)$ & $\mathrm{C} 12$ & $\mathrm{C} 11$ & $\mathrm{C} 16$ & $121.8(4)$ \\
\hline $\mathrm{O} 1$ & Rul & $\mathrm{S} 1$ & $90.37(8)$ & $\mathrm{C} 2$ & $\mathrm{C} 7$ & $\mathrm{C} 8$ & $117.4(4)$ \\
\hline $\mathrm{O} 1$ & Rul & $\mathrm{Cl1}$ & $174.71(8)$ & $\mathrm{C} 2$ & $\mathrm{C} 7$ & C6 & $119.5(4)$ \\
\hline $\mathrm{O} 1$ & Rul & $\mathrm{Cl} 2$ & $83.27(8)$ & C6 & $\mathrm{C} 7$ & $\mathrm{C} 8$ & $123.1(4)$ \\
\hline $\mathrm{O} 1$ & Rul & $\mathrm{S} 2$ & $93.79(8)$ & $\mathrm{F} 1$ & $\mathrm{C} 4$ & $\mathrm{C} 5$ & $118.7(5)$ \\
\hline N1 & Rul & S1 & $90.22(9)$ & $\mathrm{F} 1$ & $\mathrm{C} 4$ & $\mathrm{C} 3$ & $116.8(5)$ \\
\hline N1 & Rul & $\mathrm{C} 11$ & $94.92(8)$ & $\mathrm{C} 3$ & $\mathrm{C} 4$ & $\mathrm{C} 5$ & $124.5(4)$ \\
\hline N1 & Rul & $\mathrm{Cl} 2$ & $87.15(8)$ & C9 & $\mathrm{C} 8$ & $\mathrm{C} 7$ & $120.8(4)$ \\
\hline N1 & Rul & S2 & $177.06(8)$ & $\mathrm{C} 8$ & C9 & $\mathrm{C} 10$ & 121.1(3) \\
\hline N1 & Rul & $\mathrm{O} 1$ & $85.33(11)$ & $\mathrm{C} 8$ & C9 & $\mathrm{C} 1$ & $120.3(3)$ \\
\hline $\mathrm{O} 3$ & S1 & Ru1 & $114.59(13)$ & $\mathrm{C} 1$ & C9 & $\mathrm{C} 10$ & $118.5(3)$ \\
\hline $\mathrm{O} 3$ & $\mathrm{~S} 1$ & $\mathrm{C} 17$ & $107.4(2)$ & N1 & $\mathrm{C} 16$ & $\mathrm{C} 11$ & $107.9(3)$ \\
\hline $\mathrm{O} 3$ & $\mathrm{~S} 1$ & C18 & $105.5(2)$ & N1 & $\mathrm{C} 16$ & $\mathrm{C} 15$ & $131.7(4)$ \\
\hline $\mathrm{C} 17$ & S1 & Rul & $116.56(17)$ & C15 & $\mathrm{C} 16$ & $\mathrm{C} 11$ & $120.3(3)$ \\
\hline $\mathrm{C} 17$ & $\mathrm{~S} 1$ & $\mathrm{C} 18$ & 98.1(3) & $\mathrm{C} 12$ & $\mathrm{C} 13$ & $\mathrm{C} 14$ & $122.3(4)$ \\
\hline $\mathrm{C} 18$ & S1 & Rul & 112.91(19) & $\mathrm{O} 1$ & $\mathrm{C} 1$ & $\mathrm{O} 2$ & $113.2(3)$ \\
\hline $\mathrm{O} 4$ & $\mathrm{~S} 2$ & Ru1 & $120.01(14)$ & $\mathrm{O} 1$ & $\mathrm{C} 1$ & C9 & $128.6(3)$ \\
\hline $\mathrm{O} 4$ & S2 & $\mathrm{C} 20$ & $106.3(3)$ & $\mathrm{O} 2$ & $\mathrm{C} 1$ & C9 & $118.2(3)$ \\
\hline $\mathrm{O} 4$ & $\mathrm{~S} 2$ & C19 & $106.0(2)$ & C15 & $\mathrm{C} 14$ & $\mathrm{C} 13$ & $121.8(4)$ \\
\hline $\mathrm{C} 20$ & $\mathrm{~S} 2$ & Ru1 & $110.23(19)$ & C6 & $\mathrm{C} 5$ & $\mathrm{C} 4$ & $118.8(4)$ \\
\hline $\mathrm{C} 20$ & $\mathrm{~S} 2$ & C19 & 99.9(3) & $\mathrm{C} 2$ & $\mathrm{C} 3$ & $\mathrm{C} 4$ & $115.6(5)$ \\
\hline $\mathrm{C} 19$ & $\mathrm{~S} 2$ & Rul & $112.3(2)$ & C14 & $\mathrm{C} 15$ & $\mathrm{C} 16$ & $117.1(4)$ \\
\hline $\mathrm{C} 1$ & $\mathrm{O} 1$ & Ru1 & $122.1(2)$ & $\mathrm{O} 2$ & $\mathrm{C} 2$ & $\mathrm{C} 7$ & $121.6(3)$ \\
\hline $\mathrm{C} 1$ & $\mathrm{O} 2$ & $\mathrm{C} 2$ & $121.6(3)$ & $\mathrm{C} 3$ & $\mathrm{C} 2$ & $\mathrm{O} 2$ & $116.0(4)$ \\
\hline $\mathrm{C} 10$ & N1 & Rul & $123.7(2)$ & $\mathrm{C} 3$ & $\mathrm{C} 2$ & $\mathrm{C} 7$ & $122.4(4)$ \\
\hline $\mathrm{C} 10$ & N1 & $\mathrm{C} 16$ & $106.1(3)$ & $\mathrm{C} 13$ & $\mathrm{C} 12$ & $\mathrm{C} 11$ & $116.6(4)$ \\
\hline $\mathrm{C} 16$ & N1 & Rul & $130.2(2)$ & $\mathrm{C} 5$ & C6 & $\mathrm{C} 7$ & $119.1(5)$ \\
\hline $\mathrm{C} 10$ & $\mathrm{~N} 2$ & $\mathrm{C} 11$ & 107.3(3) & & & & \\
\hline
\end{tabular}

Table S7. Crystal data and structure refinement details for Ru3.

\begin{tabular}{ll}
\hline Empirical formula & $\mathrm{C}_{21} \mathrm{H}_{24} \mathrm{Cl}_{2} \mathrm{~N}_{2} \mathrm{O}_{5} \mathrm{RuS}_{2}$ \\
Formula weight & 620.51 \\
Temperature/K & $293(2)$ \\
\hline
\end{tabular}




\begin{tabular}{|c|c|}
\hline Crystal system & triclinic \\
\hline Space group & $\mathrm{P}-1$ \\
\hline $\mathrm{a} / \AA$ & $7.6382(12)$ \\
\hline $\mathrm{b} / \AA$ & $12.8303(9)$ \\
\hline $\mathrm{c} / \AA \AA$ & $13.3466(17)$ \\
\hline$\alpha /^{\circ}$ & $78.260(8)$ \\
\hline$\beta /{ }^{\circ}$ & $75.237(12)$ \\
\hline$\gamma /{ }^{\circ}$ & $88.862(8)$ \\
\hline Volume $/ \AA^{3}$ & $1237.6(3)$ \\
\hline Z & 2 \\
\hline$\rho_{\text {calc }} \mathrm{mg} / \mathrm{mm}^{3}$ & 1.665 \\
\hline $\mathrm{m} / \mathrm{mm}^{-1}$ & 1.053 \\
\hline $\mathrm{F}(000)$ & 628.0 \\
\hline Crystal size $/ \mathrm{mm}^{3}$ & $0.21 \times 0.18 \times 0.15$ \\
\hline $2 \Theta$ range for data collection & 6.736 to $52.738^{\circ}$ \\
\hline Index ranges & $-8 \leq \mathrm{h} \leq 9,-15 \leq \mathrm{k} \leq 16,-16 \leq 1 \leq 16$ \\
\hline Reflections collected & 7864 \\
\hline Independent reflections & $4936[\mathrm{R}(\mathrm{int})=0.0847]$ \\
\hline Data/restraints/parameters & $4936 / 954 / 304$ \\
\hline Goodness-of-fit on $\mathrm{F}^{2}$ & 1.053 \\
\hline Final $R$ indexes $[\mathrm{I}>=2 \sigma(\mathrm{I})]$ & $\mathrm{R}_{1}=0.1048, \mathrm{wR}_{2}=0.2155$ \\
\hline Final $\mathrm{R}$ indexes [all data] & $\mathrm{R}_{1}=0.1789, \mathrm{wR}_{2}=0.2531$ \\
\hline \multicolumn{2}{|c|}{ Largest diff. peak/hole / e $\AA^{-3} 1.79 /-1.44$} \\
\hline
\end{tabular}

Table S8. Selected bond lengths $(\AA)$ for Ru3.

\begin{tabular}{|c|c|c|c|c|c|}
\hline \multicolumn{2}{|c|}{ Atom Atom } & \multirow{2}{*}{$\frac{\text { Length/Å }}{2.406(4)}$} & \multicolumn{2}{|c|}{ Atom Atom } & \multirow{2}{*}{$\frac{\text { Length/Å }}{1.397(17)}$} \\
\hline Ru1 & Cl1 & & N2 & $\mathrm{C} 15$ & \\
\hline Ru1 & $\mathrm{Cl} 2$ & $2.420(4)$ & $\mathrm{N} 2$ & $\mathrm{C} 16$ & $1.327(16)$ \\
\hline Ru1 & S1 & $2.231(4)$ & $\mathrm{C} 10$ & $\mathrm{C} 11$ & $1.39(2)$ \\
\hline Ru1 & S2 & $2.253(4)$ & $\mathrm{C} 10$ & $\mathrm{C} 15$ & $1.416(18)$ \\
\hline Ru1 & $\mathrm{O} 3$ & $2.125(9)$ & $\mathrm{C} 11$ & $\mathrm{C} 12$ & $1.38(2)$ \\
\hline Ru1 & $\mathrm{N} 2$ & $2.137(11)$ & $\mathrm{C} 12$ & $\mathrm{C} 13$ & $1.38(2)$ \\
\hline S1 & O1 & $1.481(10)$ & $\mathrm{C} 13$ & $\mathrm{C} 14$ & $1.409(19)$ \\
\hline S1 & C6 & $1.776(17)$ & $\mathrm{C} 14$ & $\mathrm{C} 15$ & $1.379(19)$ \\
\hline S1 & $\mathrm{C} 7$ & $1.782(15)$ & $\mathrm{C} 16$ & $\mathrm{C} 17$ & $1.483(18)$ \\
\hline S2 & $\mathrm{O} 2$ & $1.472(10)$ & $\mathrm{C} 17$ & $\mathrm{C} 18$ & $1.420(19)$ \\
\hline S2 & $\mathrm{C} 8$ & $1.782(15)$ & $\mathrm{C} 17$ & $\mathrm{C} 26$ & $1.345(18)$ \\
\hline S2 & C9 & $1.776(15)$ & C19 & $\mathrm{C} 20$ & $1.383(18)$ \\
\hline $\mathrm{O} 3$ & $\mathrm{C} 18$ & $1.244(14)$ & C19 & $\mathrm{C} 25$ & $1.399(19)$ \\
\hline $\mathrm{O} 4$ & $\mathrm{C} 18$ & $1.367(15)$ & $\mathrm{C} 20$ & $\mathrm{C} 21$ & $1.378(18)$ \\
\hline $\mathrm{O} 4$ & C19 & $1.382(15)$ & $\mathrm{C} 21$ & $\mathrm{C} 23$ & $1.39(2)$ \\
\hline $\mathrm{O} 5$ & $\mathrm{C} 21$ & $1.357(15)$ & $\mathrm{C} 23$ & $\mathrm{C} 24$ & $1.387(19)$ \\
\hline O5 & $\mathrm{C} 22$ & $1.440(18)$ & $\mathrm{C} 24$ & $\mathrm{C} 25$ & $1.404(18)$ \\
\hline N1 & $\mathrm{C} 14$ & $1.402(16)$ & $\mathrm{C} 25$ & $\mathrm{C} 26$ & $1.412(18)$ \\
\hline
\end{tabular}




\begin{tabular}{lll}
\hline N1 & C16 & $1.383(17)$ \\
\hline
\end{tabular}

Table S9. Selected bond angles ( ${ }^{\circ}$ ) for Ru3.

\begin{tabular}{|c|c|c|c|c|c|c|c|}
\hline \multicolumn{3}{|c|}{ Atom Atom Atom } & \multirow{2}{*}{$\frac{\text { Angle } /^{\circ}}{93.04(14)}$} & \multicolumn{3}{|c|}{ Atom Atom Atom } & \multirow{2}{*}{$\frac{\text { Angle }^{\circ}}{105.3(11)}$} \\
\hline $\mathrm{Cl1}$ & Rul & $\mathrm{Cl} 2$ & & $\mathrm{C} 16$ & $\mathrm{~N} 2$ & $\mathrm{C} 15$ & \\
\hline $\mathrm{S} 1$ & Rul & Cl1 & $92.73(14)$ & $\mathrm{C} 11$ & $\mathrm{C} 10$ & $\mathrm{C} 15$ & $114.7(14)$ \\
\hline $\mathrm{S} 1$ & Ru1 & $\mathrm{Cl} 2$ & $173.53(15)$ & $\mathrm{C} 12$ & $\mathrm{C} 11$ & $\mathrm{C} 10$ & $123.7(14)$ \\
\hline $\mathrm{S} 1$ & Rul & S2 & $93.27(14)$ & $\mathrm{C} 13$ & $\mathrm{C} 12$ & $\mathrm{C} 11$ & $121.9(14)$ \\
\hline $\mathrm{S} 2$ & Rul & $\mathrm{C} 11$ & $85.68(13)$ & $\mathrm{C} 12$ & $\mathrm{C} 13$ & $\mathrm{C} 14$ & $115.4(14)$ \\
\hline $\mathrm{S} 2$ & Ru1 & $\mathrm{C} 12$ & $90.08(14)$ & N1 & $\mathrm{C} 14$ & $\mathrm{C} 13$ & $129.3(14)$ \\
\hline $\mathrm{O} 3$ & Rul & $\mathrm{Cl1}$ & $175.8(3)$ & $\mathrm{C} 15$ & $\mathrm{C} 14$ & N1 & $107.8(12)$ \\
\hline $\mathrm{O} 3$ & Rul & $\mathrm{Cl} 2$ & $84.6(3)$ & $\mathrm{C} 15$ & $\mathrm{C} 14$ & $\mathrm{C} 13$ & $122.9(13)$ \\
\hline $\mathrm{O} 3$ & Ru1 & S1 & $89.8(3)$ & N2 & $\mathrm{C} 15$ & $\mathrm{C} 10$ & $129.5(13)$ \\
\hline $\mathrm{O} 3$ & Rul & $\mathrm{S} 2$ & $90.8(3)$ & C14 & $\mathrm{C} 15$ & $\mathrm{~N} 2$ & $109.1(11)$ \\
\hline $\mathrm{O} 3$ & Rul & $\mathrm{N} 2$ & $85.4(4)$ & $\mathrm{C} 14$ & $\mathrm{C} 15$ & $\mathrm{C} 10$ & $121.4(13)$ \\
\hline $\mathrm{N} 2$ & Rul & $\mathrm{C} 11$ & $98.0(3)$ & N1 & $\mathrm{C} 16$ & $\mathrm{C} 17$ & $118.6(12)$ \\
\hline $\mathrm{N} 2$ & Rul & $\mathrm{Cl} 2$ & $86.0(3)$ & $\mathrm{N} 2$ & $\mathrm{C} 16$ & N1 & $113.4(12)$ \\
\hline $\mathrm{N} 2$ & Ru1 & S1 & $90.4(3)$ & $\mathrm{N} 2$ & $\mathrm{C} 16$ & $\mathrm{C} 17$ & $128.0(13)$ \\
\hline $\mathrm{N} 2$ & Ru1 & S2 & $174.7(3)$ & C18 & $\mathrm{C} 17$ & $\mathrm{C} 16$ & $119.3(12)$ \\
\hline $\mathrm{O} 1$ & S1 & Ru1 & $115.4(4)$ & $\mathrm{C} 26$ & $\mathrm{C} 17$ & $\mathrm{C} 16$ & $122.5(13)$ \\
\hline $\mathrm{O} 1$ & S1 & C6 & $104.8(7)$ & $\mathrm{C} 26$ & $\mathrm{C} 17$ & $\mathrm{C} 18$ & $118.2(13)$ \\
\hline $\mathrm{O} 1$ & S1 & $\mathrm{C} 7$ & $105.3(7)$ & $\mathrm{O} 3$ & $\mathrm{C} 18$ & $\mathrm{O} 4$ & $112.0(12)$ \\
\hline C6 & $\mathrm{S} 1$ & Ru1 & $112.6(6)$ & $\mathrm{O} 3$ & C18 & $\mathrm{C} 17$ & $127.8(12)$ \\
\hline C6 & S1 & $\mathrm{C} 7$ & $99.2(8)$ & $\mathrm{O} 4$ & $\mathrm{C} 18$ & $\mathrm{C} 17$ & $120.1(11)$ \\
\hline $\mathrm{C} 7$ & S1 & Ru1 & $117.6(6)$ & $\mathrm{O} 4$ & C19 & $\mathrm{C} 20$ & $116.4(12)$ \\
\hline $\mathrm{O} 2$ & $\mathrm{~S} 2$ & Ru1 & $118.2(4)$ & $\mathrm{O} 4$ & C19 & $\mathrm{C} 25$ & $120.3(12)$ \\
\hline $\mathrm{O} 2$ & $\mathrm{~S} 2$ & $\mathrm{C} 8$ & $106.5(7)$ & $\mathrm{C} 20$ & C19 & $\mathrm{C} 25$ & $123.2(12)$ \\
\hline $\mathrm{O} 2$ & S2 & C9 & $106.9(7)$ & $\mathrm{C} 21$ & $\mathrm{C} 20$ & C19 & $117.5(14)$ \\
\hline $\mathrm{C} 8$ & S2 & Ru1 & $111.1(6)$ & $\mathrm{O} 5$ & $\mathrm{C} 21$ & $\mathrm{C} 20$ & $124.4(14)$ \\
\hline $\mathrm{C} 9$ & S2 & Ru1 & $113.7(6)$ & $\mathrm{O} 5$ & $\mathrm{C} 21$ & $\mathrm{C} 23$ & $114.9(12)$ \\
\hline $\mathrm{C} 9$ & $\mathrm{~S} 2$ & $\mathrm{C} 8$ & $98.5(8)$ & $\mathrm{C} 20$ & $\mathrm{C} 21$ & $\mathrm{C} 23$ & $120.7(13)$ \\
\hline $\mathrm{C} 18$ & $\mathrm{O} 3$ & Ru1 & $121.8(9)$ & $\mathrm{C} 24$ & $\mathrm{C} 23$ & $\mathrm{C} 21$ & $121.5(13)$ \\
\hline $\mathrm{C} 18$ & $\mathrm{O} 4$ & C19 & $120.9(11)$ & $\mathrm{C} 23$ & $\mathrm{C} 24$ & $\mathrm{C} 25$ & $118.5(14)$ \\
\hline $\mathrm{C} 21$ & $\mathrm{O} 5$ & $\mathrm{C} 22$ & $117.8(11)$ & C19 & $\mathrm{C} 25$ & $\mathrm{C} 24$ & $118.2(13)$ \\
\hline $\mathrm{C} 16$ & N1 & C14 & $104.4(11)$ & C19 & $\mathrm{C} 25$ & $\mathrm{C} 26$ & $117.1(12)$ \\
\hline $\mathrm{C} 15$ & N2 & Ru1 & $132.1(9)$ & $\mathrm{C} 24$ & $\mathrm{C} 25$ & $\mathrm{C} 26$ & $124.6(14)$ \\
\hline C16 & N2 & Ru1 & $122.4(9)$ & $\mathrm{C} 17$ & $\mathrm{C} 26$ & $\mathrm{C} 25$ & $123.2(14)$ \\
\hline
\end{tabular}



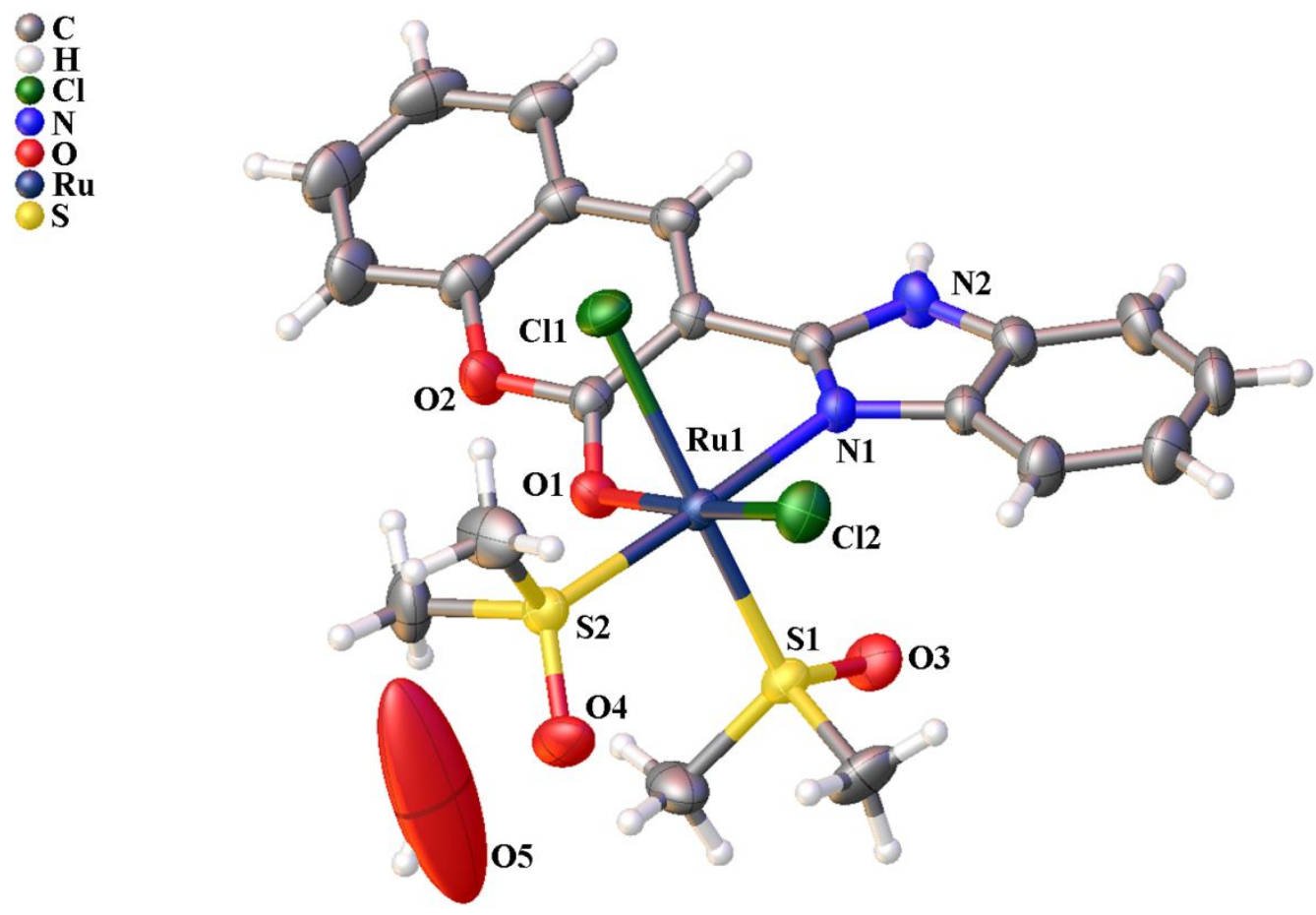

Figure S11. Crystal structures of Ru1.
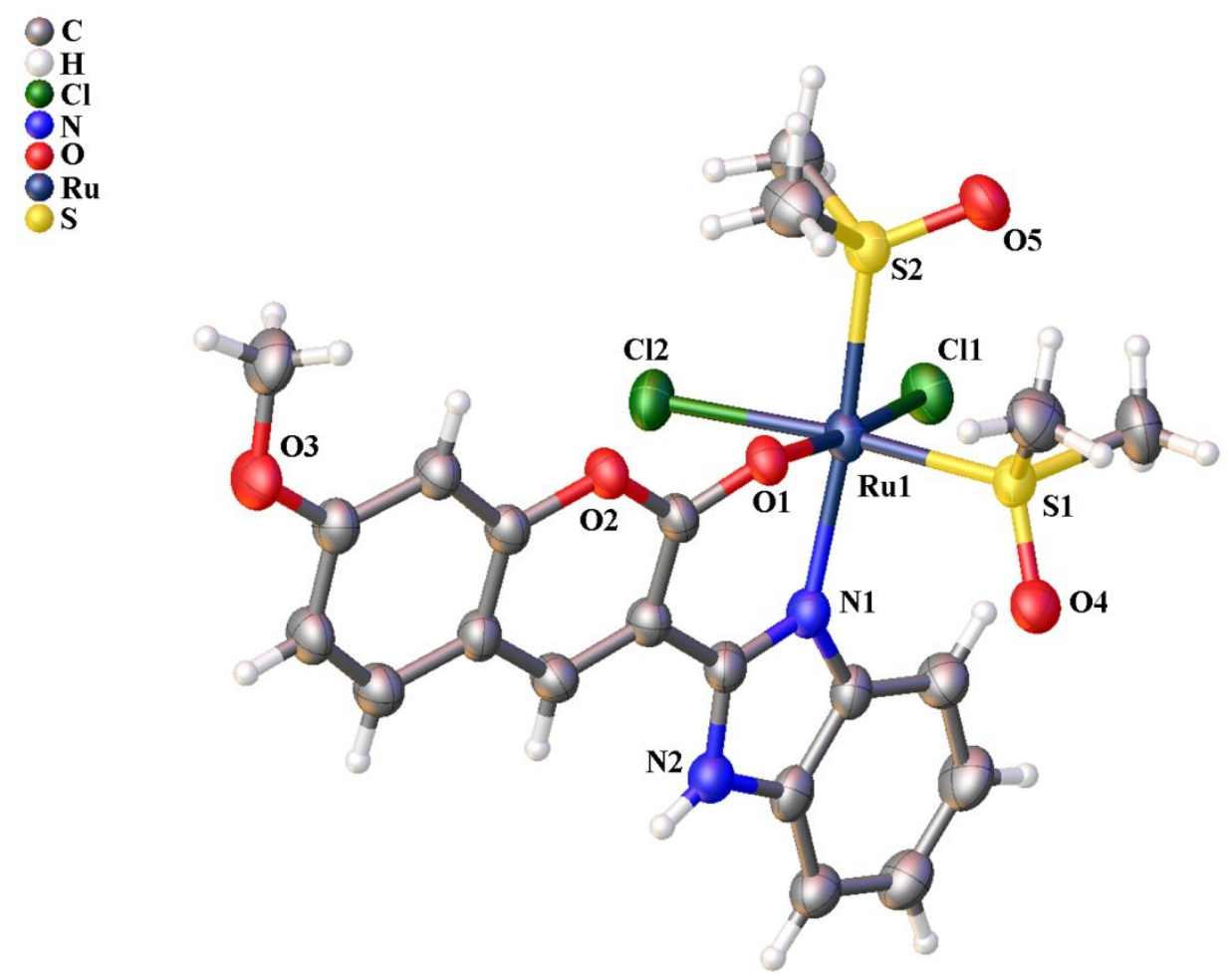

Figure S12. Crystal structures of Ru3. 
Table S10. $\mathrm{IC}_{50}$ values $(\mu \mathrm{M})$ of each compound against the human selected cell lines

a

\begin{tabular}{|c|c|c|c|c|c|c|}
\hline & NCI-H460 & $\mathrm{T}-24$ & SK-OV-3 & MGC80-3 & A549 & HL-7702 \\
\hline $\mathrm{L}^{\mathrm{a}}$ & $>100$ & $>150$ & $>150$ & $>100$ & $>100$ & $>100$ \\
\hline Ru1 & $15.78 \pm 1.02$ & $53.01 \pm 1.26$ & $65.02 \pm 1.12$ & $91.03 \pm 1.01$ & $41.36 \pm 0.99$ & $>100$ \\
\hline $\mathrm{L}^{\mathrm{b}}$ & $>100$ & $>100$ & $>100$ & $>100$ & $>100$ & $>100$ \\
\hline Ru2 & $0.30 \pm 0.02$ & $25.63 \pm 1.44$ & $35.69 \pm 2.03$ & $68.69 \pm 1.15$ & $20.14 \pm 0.28$ & $>100$ \\
\hline $\mathrm{L}^{\mathrm{c}}$ & $>100$ & $>100$ & $>100$ & $>100$ & $>100$ & $>100$ \\
\hline Ru3 & $10.04 \pm 0.73$ & $30.00 \pm 1.09$ & $46.25 \pm 1.59$ & $88.24 \pm 1.79$ & $34.39 \pm 1.05$ & $>100$ \\
\hline$c i s-\mathrm{RuCl}_{2}(\mathrm{DMSO})_{4}$ & $>100$ & $>100$ & $>100$ & $>100$ & $>100$ & $>100$ \\
\hline cisplatin ${ }^{b}$ & $13.25 \pm 1.18$ & $17.03 \pm 0.57$ & $15.09 \pm 0.91$ & $12.06 \pm 1.18$ & $12.36 \pm 0.19$ & $17.03 \pm 1.06$ \\
\hline
\end{tabular}

${ }^{\mathrm{a}} \mathrm{IC}_{50}=$ mean $\pm \mathrm{SD}$ (standard error of the mean) $(\mathrm{n}=5)$. These six human cancer and normal cells were treated with the ligands and each $\mathrm{Ru}$ complex for $48 \mathrm{~h} .{ }^{\mathrm{b}}$ Cisplatin $(1.0 \mathrm{mM})$ was prepared in $0.154 \mathrm{M} \mathrm{NaCl}^{1-7}$

Table S11. Cellular distribution of Ru2 $(0.30 \mu \mathrm{M})$ and Ru1 $(15.78 \mu \mathrm{M})$ in NCI-H460 cancer cells after $24 \mathrm{~h}$ of incubation.

\begin{tabular}{cccc}
\hline & total & nuclear fraction & mitochondrial fraction \\
\hline Ru2 & $(4.58 \pm 0.11 \mathrm{nmol}$ of & $(2.01 \pm 0.13 \mathrm{nmol}$ of & $(0.28 \pm 0.15 \mathrm{nmol}$ of \\
& $\mathrm{Ru}) / 10^{6}$ cells & $\mathrm{Ru}) / 10^{6} \mathrm{cells}$ & $\mathrm{Ru}) / 10^{6} \mathrm{cells}$ \\
$\mathbf{R u 1}$ & $(1.56 \pm 0.14 \mathrm{nmol}$ of & $(0.52 \pm 0.17 \mathrm{nmol}$ of & $(0.33 \pm 0.11 \mathrm{nmol}$ of \\
& $\mathrm{Ru}) / 10^{6}$ cells & $\mathrm{Ru}) / 10^{6}$ cells & $\mathrm{Ru}) / 10^{6} \mathrm{cells}$ \\
\hline
\end{tabular}



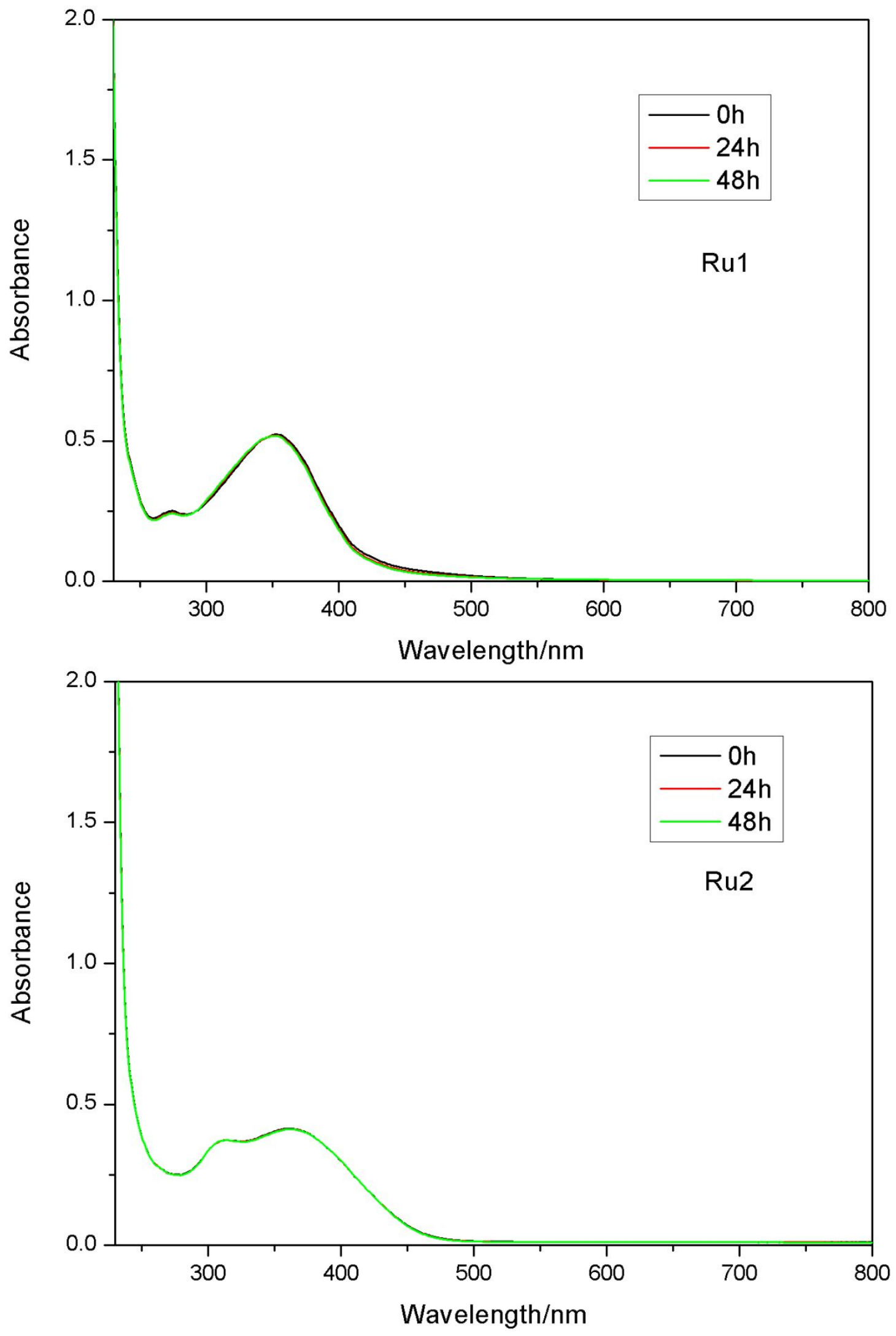


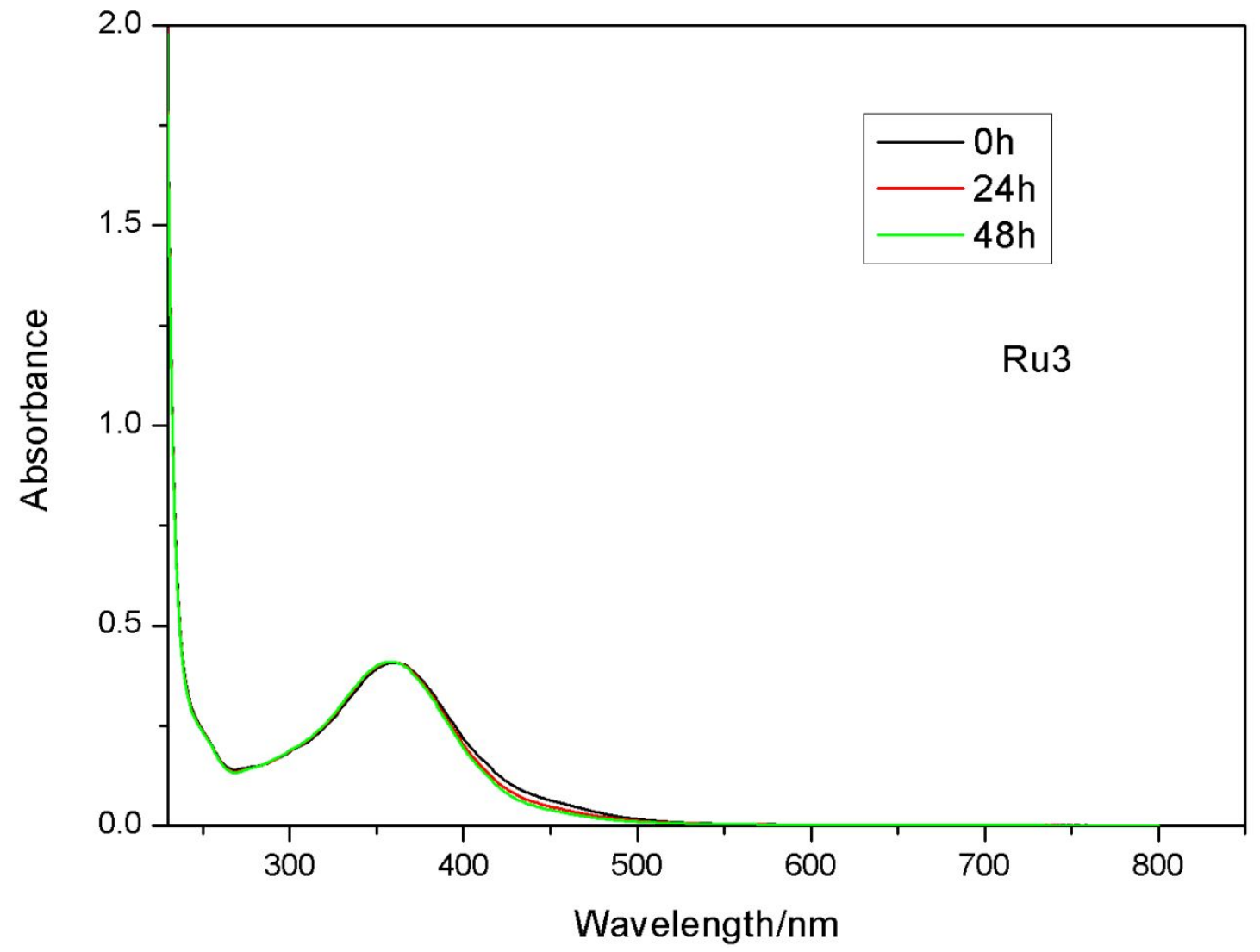

Figure S13. UV-Vis absorption spectra of Ru1-Ru3 $\left(2.0 \times 10^{-5} \mathrm{M}\right)$ in TBS (Tris-HCl buffer solution, $10 \mathrm{mM}, \mathrm{pH} 7.35$ ) solution in the time course 0,24 and $48 \mathrm{~h}$, respectively.

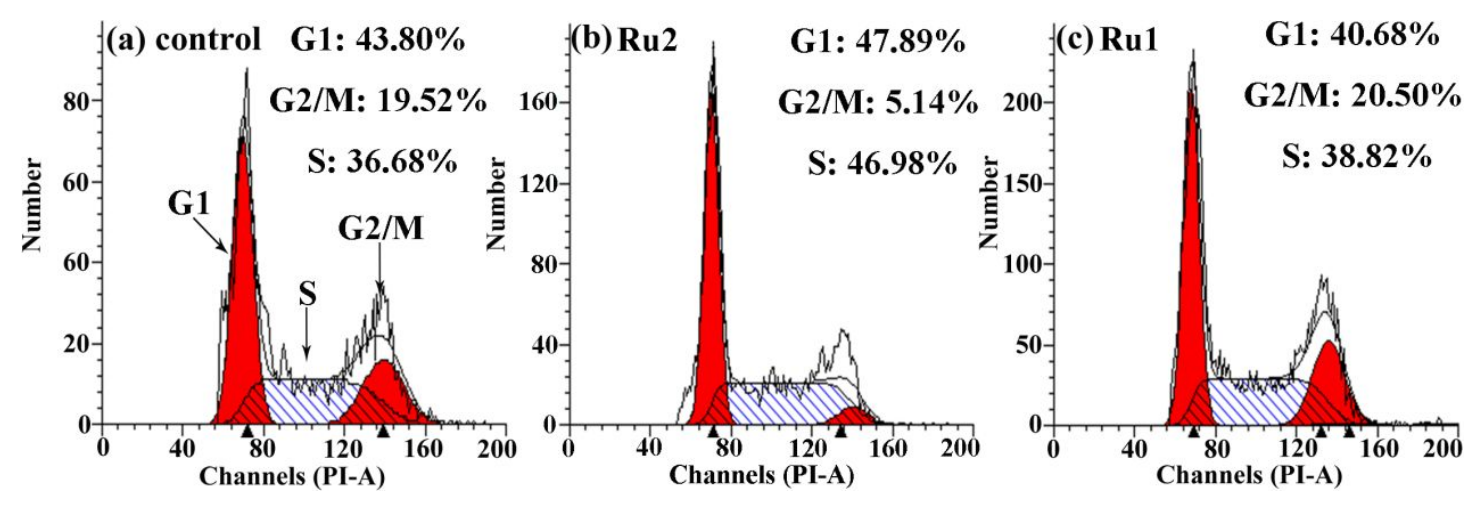

Figure S14. Cell cycle distribution of NCI-H460 cells exposure to Ru2 $(0.30 \mu \mathrm{M})$ and Ru1 (15.78 $\mu \mathrm{M})$ for $24 \mathrm{~h}$. 

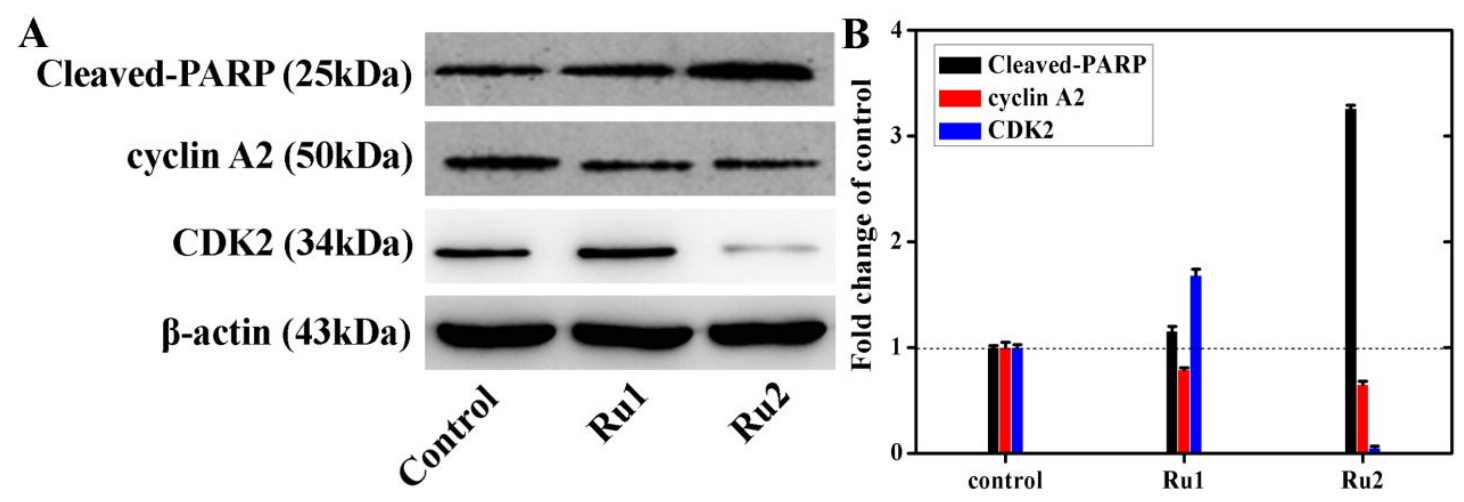

Figure S15. The protein levels of cyclin A2, cleaved-PARP and CDK2 in NCI-H460 cells treated of $\mathbf{R u 2}(0.30 \mu \mathrm{M})$ and $\mathbf{R u} 1(15.78 \mu \mathrm{M})$ at $24 \mathrm{~h}$ was examined by Western blot assay, respectively. 


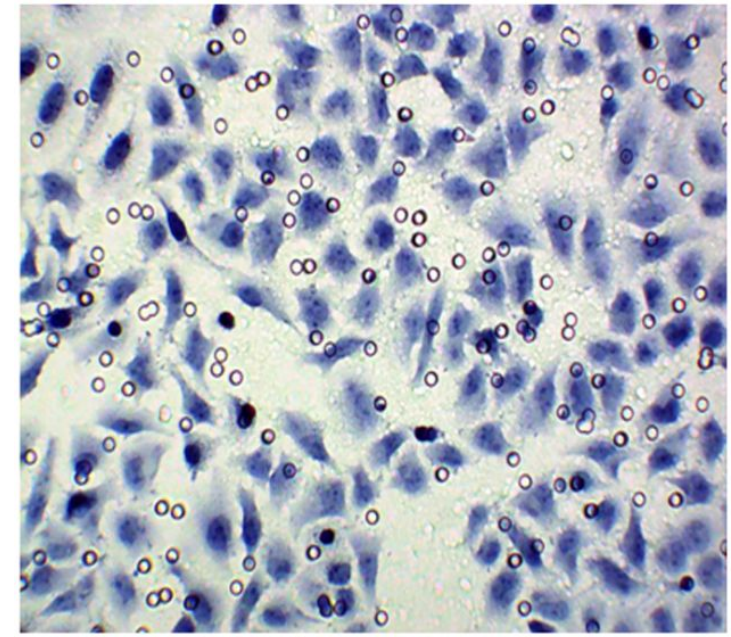

(a) control

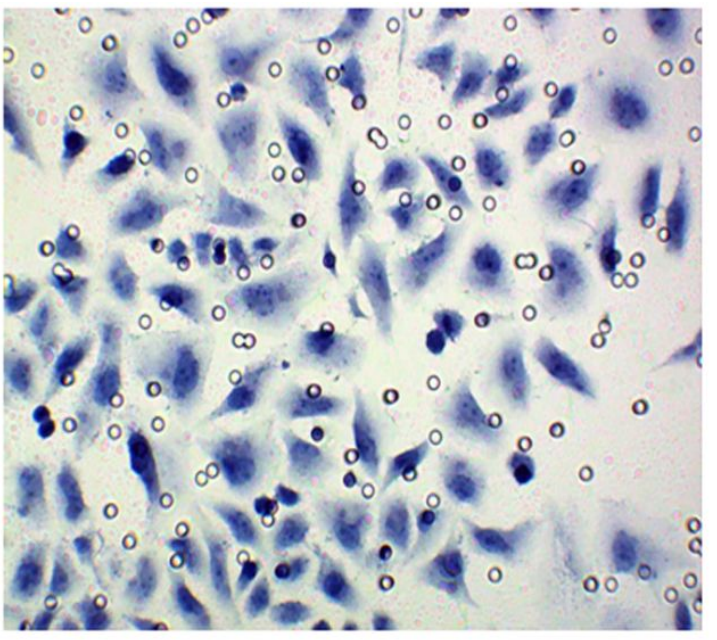

(b) Ru1

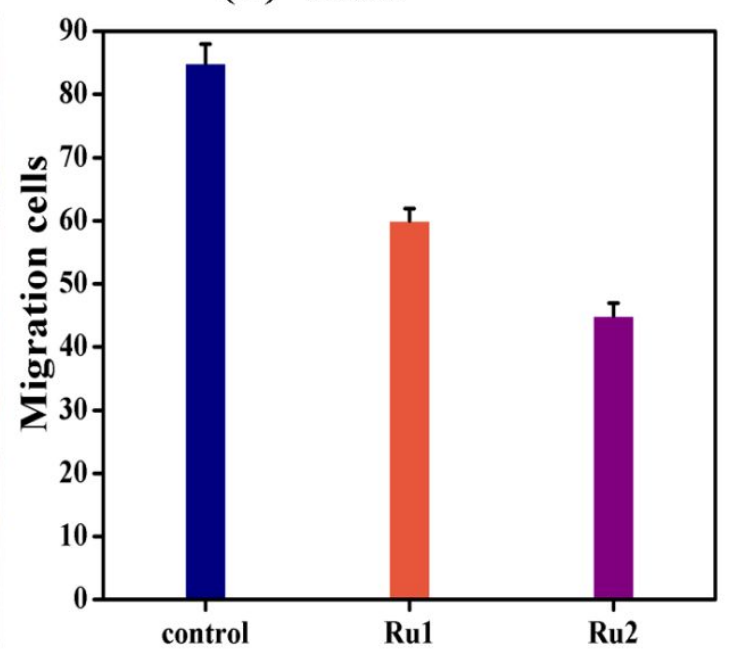

(d) statistical result

Figure S16. Migration inhibition induced by $\mathbf{R u 2}(0.30 \mu \mathrm{M})$ and $\mathbf{R u 1}(15.78 \mu \mathrm{M})$ in NCI-H460 cells at $24 \mathrm{~h}$. 


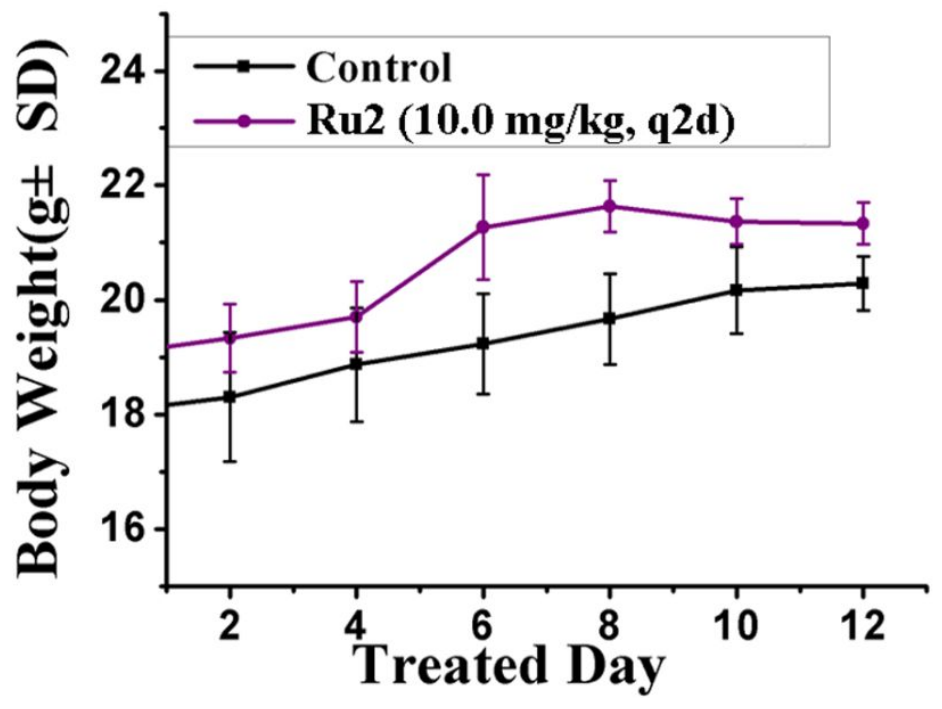

Figure S17. Changes in body weight of ICR mice administered with maximum administration dose of $\mathbf{R u} 2$ (10.0 mg/kg every 2 days (q2d)). Groups of ICR mice (n =6) received either vehicle; the second group of mice received $\mathbf{R u} 2(10.0 \mathrm{mg} / \mathrm{kg}$ every 2 days (q2d)), and then monitored for 2 days. The animals were weighed daily.

Table S12. The tumor volume in treated and non-treated mice from the date of surgery to the study end point in the NCI-H460 xenograft model after Ru2 treated.

\begin{tabular}{cccc}
\hline Group & \multicolumn{2}{c}{ Tumor Volume $\left(\mathbf{m m}^{\mathbf{3}}\right)$} & T/C \\
& (start) & (end) & (\%) \\
\hline Control & $72.42 \pm 12.94$ & $1544.41 \pm 225.83$ & - \\
Ru2 $(10.0 \mathrm{mg} / \mathrm{kg})$ & $72.36 \pm 12.13$ & $477.69 \pm 184.43$ & $30.9^{\mathrm{a}}$ \\
\hline
\end{tabular}

${ }^{\mathrm{a}}$ mean $p<0.05, \quad p v s$ vehicle control 
Table S13. Average body weight in treated and non-treated mice from the date of surgery to the study in the NCI-H460 xenogfart model after Ru2 treated.

\begin{tabular}{cccc}
\hline Group & \multicolumn{2}{c}{ Body Weight (g) } & RBW (\%) \\
& (start) & (end) & (end) \\
\hline Control & $18.03 \pm 1.28$ & $20.28 \pm 0.47$ & 112.48 \\
Ru2 $(10.0 \mathrm{mg} / \mathrm{kg})$ & $19.03 \pm 0.67$ & $21.33 \pm 0.37$ & 112.09 \\
\hline
\end{tabular}

Table S14. In vivo anti-cancer activity of Ru2 toward NCI-H460 cancer Xenograft.

\begin{tabular}{ccc}
\hline Group & $\begin{array}{r}\text { average tumor } \\
\text { weight(mean } \pm \text { SD g) }\end{array}$ & $\begin{array}{c}\text { inhibition of tumor } \\
\text { growth(\%) }\end{array}$ \\
\hline Control & $1.56 \pm 0.14$ & - \\
Ru2 $(10.0 \mathrm{mg} / \mathrm{kg})$ & $0.60 \pm 0.21$ & $61.3^{\mathrm{a}}$ \\
\hline
\end{tabular}

${ }^{a}$ mean $p<0.05, \quad p v s$ control.

\section{Experimental Sections}

\section{Synthesis of ligands}

0.01 mol 2-cyanomethylbenzimidazole and $0.01 \mathrm{~mol}$ salicylaldehyde (or 4-fluoro-2-hydroxybenzaldehyde, and 4-methoxyl-2-hydroxybenzaldehyde) were added to ethanol $(50.0 \mathrm{~mL})$. Piperidine $(0.1 \mathrm{~mL})$ was then added and the mixture stirred at room temperature for $6.0 \mathrm{~h}$. The yellow precipitate which gradually separated out of the solution was collected and heated under reflux in $2 \%$ aqueous hydrochloric acid solution $(250.0 \mathrm{~mL})$ for $6 \mathrm{~h}$. The mixture was cooled and excess sodium acetate added. The precipitate of 3-(2'-benzimidazolyl)coumarin $\left(\mathrm{L}^{\mathrm{a}}\right)$, 
3-(2'-benzimidazolyl)-7-methoxyl-coumarin $\left(\mathrm{L}^{\mathrm{c}}\right)$ was then filtered, washed with water, dried and recrystallised from ethanol as orange products.

Data for $\mathrm{L}^{\mathrm{c}}$. Yield: $77.09 \%$. ESI-MS: $\mathrm{m} / \mathrm{z}=314.9$ for $[\mathrm{M}+\mathrm{Na}]^{+}$. Elemental analysis: calcd (\%) for $\mathrm{C}_{17} \mathrm{H}_{12} \mathrm{~N}_{2} \mathrm{O}_{3}$ : C 69.86, $\mathrm{H} 4.14$, N 9.58; found: $\mathrm{C} 69.83, \mathrm{H} 4.19$, N 9.56.

Data for $\mathrm{L}^{\mathrm{a}}$. Yield: $85.69 \%$. ESI-MS: $\mathrm{m} / \mathrm{z}=263.0$ for $[\mathrm{M}+\mathrm{H}]^{+}$. Elemental analysis: calcd (\%) for $\mathrm{C}_{16} \mathrm{H}_{10} \mathrm{~N}_{2} \mathrm{O}_{2}$ : C 73.27, H 3.84, N 10.68; found: C 73.25, H 3.87, N 10.66 .

Data for $\mathrm{L}^{\mathrm{b}}$. Yield: $81.14 \%$. ESI-MS: $\mathrm{m} / \mathrm{z}=281.0$ for $[\mathrm{M}+\mathrm{H}]^{+}$. Elemental analysis: calcd (\%) for $\mathrm{C}_{16} \mathrm{H}_{9} \mathrm{FN}_{2} \mathrm{O}_{2}$ : C 68.57, $\mathrm{H} 3.24, \mathrm{~N} 10.00$; found: $\mathrm{C} 68.54, \mathrm{H}$ 3.36, N 9.96.

\section{Synthesis and characterization of Ru1-Ru3}

$c i s-\mathrm{RuCl}_{2}(\mathrm{DMSO})_{4} \quad\left(\begin{array}{ll}1.0 & \mathrm{mmol})\end{array}\right.$ was mixed with $1.0 \quad \mathrm{mmol}$ 3-(2'-benzimidazolyl)coumarin $\left(\mathrm{L}^{\mathrm{a}}\right), \quad 3-\left(2^{\prime}\right.$-benzimidazolyl)-7-fluoro-coumarin $\left(\mathrm{L}^{\mathrm{b}}\right)$ and 3-(2'-benzimidazolyl)-7-methoxyl-coumarin $\left(\mathrm{L}^{\mathrm{c}}\right)$ in $\mathrm{CH}_{3} \mathrm{OH}(15.0 \mathrm{~mL})$ and $\mathrm{CH}_{2} \mathrm{Cl}_{2}(6.0 \mathrm{~mL})$ at $60{ }^{\circ} \mathrm{C}$ for $12.0 \mathrm{~h}$ to yield red brown rod-shaped crystals of $\left[\mathrm{RuCl}_{2}\left(\mathrm{~L}^{\mathrm{a}}\right)(\mathrm{DMSO})_{2}\right] \cdot \mathrm{H}_{2} \mathrm{O} \quad(\mathbf{R u 1}), \quad\left[\mathrm{RuCl}_{2}\left(\mathrm{~L}^{\mathrm{b}}\right)(\mathrm{DMSO})_{2}\right] \quad(\mathbf{R u} 2) \quad$ and $\left[\mathrm{RuCl}_{2}\left(\mathrm{~L}^{\mathrm{c}}\right)(\mathrm{DMSO})_{2}\right](\mathbf{R u 3})$, which were isolated and characterized.

Data for Ru3. Yield: $80.32 \%$. ESI-MS: m/z = 585.1 for [M-Cl] $]^{+}$. IR (KBr): 3459, $3069,3007,1648,1592,1450,1278,1237,1117,1089,1066,1018,742,685,511$, $428 \mathrm{~cm}^{-1}$. Elemental analysis: calcd (\%) for $\mathrm{C}_{21} \mathrm{H}_{24} \mathrm{Cl}_{2} \mathrm{~N}_{2} \mathrm{O}_{5} \mathrm{RuS}_{2}$ : C 40.65, H 3.90, N 4.51; found: C 40.61, H 3.93, N 4.49 .

Data for Ru1. Yield: 90.24\%. ESI-MS: m/z = 555.1 for [M-Cl] $]^{+}$IR (KBr): 3427, $3087,3005,1642,1590,1446,1325,1220,1073,1017,971,930,767,747,681,580$, 
$427 \mathrm{~cm}^{-1}$. Elemental analysis: calcd (\%) for $\mathrm{C}_{20} \mathrm{H}_{22} \mathrm{Cl}_{2} \mathrm{~N}_{2} \mathrm{O}_{4} \mathrm{RuS}_{2}$ : C 40.68, H 3.76, N 4.74; found: C 40.65, H 3.80, N 4.72.

Data for Ru2. Yield: $85.17 \%$. ESI-MS: m/z= 572.1 for [M-Cl] $]^{+}$. IR (KBr): 3434, $3080,3015,1646,1587,1450,1264,1227,1151,1086,1018,841,768,719,682,628$, 503, $427 \mathrm{~cm}^{-1}$. Elemental analysis: calcd (\%) for $\mathrm{C}_{20} \mathrm{H}_{21} \mathrm{Cl}_{2} \mathrm{FN}_{2} \mathrm{O}_{4} \mathrm{RuS}_{2}$ : C 39.48, $\mathrm{H}$ 3.48, N 4.60; found: C 39.45, H 3.51, N 4.58.

\section{Materials and methods}

The X-ray crystallography structures of Ru1-Ru3 were determined in accordance with previously reported methods. ${ }^{8}$ The antitumor mechanisms of Ru1-Ru3 were in accordance with the reported procedures of Sadler, Chao and Liang. ${ }^{1-11}$

\subsection{X-ray Crystallography}

The data collection of single crystals of Ru1-Ru3 was performed on a SuperNova $\mathrm{CCD}$ diffractometer equipped with graphite monochromated Mo $\mathrm{K} \alpha$ radiation $(\lambda=$ $0.71073 \AA$ ) at room temperature. The structures were solved with direct methods and refined using SHELX-97 programs. ${ }^{11}$ The nonhydrogen atoms were located in successive difference Fourier synthesis. The final refinement was performed by full-matrix leastsquares methods with anisotropic thermal parameters for no-hydrogen atoms on $F_{2}$. The hydrogen atoms were added theoretically and riding on the concerned atoms. The paramerters used intensity collection and refinements are summarized in Tables S1-S9 together with the crystal data.

\subsection{Cytotoxicity assay}

The cell culture was maintained on RPMI-1640 medium supplemented with $10 \%$ fetal bovine serum, $100 \mathrm{U} / \mathrm{mL}$ penicillin and $100 \mu \mathrm{g} / \mathrm{mL}$ streptomycin in $25 \mathrm{~cm}^{2}$ culture flasks at $37{ }^{\circ} \mathrm{C}$ humidified atmosphere with $5 \% \mathrm{CO}_{2}$. All cells to be tested in the following assays have a passage number of 3-6. 
Cells $5.0 \times 10^{3}$ per well were seeded in triplicate in 96-well plates and incubated for $24 \mathrm{~h}$ at $37{ }^{\circ} \mathrm{C}$ and $5 \% \mathrm{CO}_{2} / 95 \%$ air. Then graded amounts of compound were added to the wells in $10 \mu \mathrm{L}$ of FBS free culture medium and the plates were incubated in a $5 \%$ $\mathrm{CO}_{2}$ humidified atmosphere for $48 \mathrm{~h}$. Six replica wells were used as controls. Cells were grew for $12 \mathrm{~h}$ before treatment to reach $70 \%$ confluency and $20 \mu \mathrm{L}$ of tested various concentrations of compounds were added to each well. The final concentration of the tested compounds were kept at 1.25, 2.5, 5, 10, $20 \mu \mathrm{M}$, respectively. After $48 \mathrm{~h}$ of culture, $0.1 \mathrm{mg}$ of MTT (in $20 \mu \mathrm{L}$ of PBS) was added to each well, and cells were incubated at $37^{\circ} \mathrm{C}$ for $6 \mathrm{~h}$. The formed formazan crystals were then dissolved in $100 \mu \mathrm{L}$ of DMSO and the absorbance was read by enzyme labeling instrument with 490/630 nm double wavelength measurement. The final $\mathrm{IC}_{50}$ values were calculated by the Bliss method $(n=5)$. All tests were repeated in at least three independent trials.

\subsection{Uptake of Ru in tumor cells}

The tumor cells ( 10 million cells) were treated with $\mathbf{R u 2}(0.30 \mu \mathrm{M})$ and $\mathbf{R u 1}(15.78$ $\mu \mathrm{M}$ ) for $24 \mathrm{~h}$ at $37{ }^{\circ} \mathrm{C}$ in a humidified $5 \% \mathrm{CO}_{2}$ incubator. The spent media was removed, and the cells were washed with $5 \mathrm{~mL}$ of PBS, scraped, and collected in 5 $\mathrm{mL}$ of PBS. The scrapped cells were spun down, by centrifuging at $2500 \mathrm{rpm}$ for 10 min. The cell pellet obtained was dissolved in $1 \mathrm{M} \mathrm{NaOH}(1 \mathrm{~mL})$ and diluted with $2 \%$ (v/v) $\mathrm{HNO}_{3}(5 \mathrm{~mL})$ for determining whole cell $\mathrm{Ru}$ content. Another set was treated similarly, nuclear fraction, nuclear proteins, membrane proteins and cytoplasmic protein were isolated, and the final solution was made up to $5 \mathrm{~mL}$ using $2 \%(\mathrm{v} / \mathrm{v})$ $\mathrm{HNO}_{3}$. The amount of cobalt taken up by the cells was determined by ICP-MS. The instrument was calibrated for $\mathrm{Ru}$ complexes using standard solutions containing 10, 50, 100, 500 and $1000 \mathrm{ppb} \mathrm{Ru}$. 


\subsection{Apoptosis analysis}

Apoptosis was detected by flow cytometric analysis of annexin V staining. Annexin V-FITC vs PI assay was performed as previously described. Briefly, adherent cancer cells were harvested and suspended in the annexin-binding buffer $\left(5 \times 10^{5}\right.$ cells $\left./ \mathrm{mL}\right)$. Then, tumor cells were incubated with annexin V-FITC and PI for $1 \mathrm{~h}$ at room temperature in the dark and immediately analyzed by flow cytometry. The data are presented as biparametric dot plots showing PI red fluorescence vs annexin V-FITC green fluorescence.

\subsection{Cell cycle analysis}

In cell cycle analysis, the cancer cells were maintained with $10 \%$ fetal calf serum in $5 \% \mathrm{CO}_{2}$ at $37^{\circ} \mathrm{C}$. Cells were harvested by trypsinization and rinsed with PBS. After centrifugation, the pellet $\left(10^{5}-10^{6}\right.$ cells $)$ was suspended in $1 \mathrm{~mL}$ PBS. The cells were washed in PBS and fixed with ice-cold 70\% ethanol in PBS under violent shaking. Cells $1 \times 10^{6}$ were centrifuged and resuspended in a staining solution $(0.5 \mathrm{~mL}$ of PBS containing $50 \mu \mathrm{g} / \mathrm{mL}$ PI and $75 \mathrm{kU} / \mathrm{mL}$ RNase A) for $30 \mathrm{~min}$ at room temperature in the dark. Finally, the cell cycle was analyzed by FACS Calibur flow cytometer (BD) and the cell cycle distribution and percentage of apoptotic cells were analyzed using Cell Quest (BDIS) and ModFit LT (Verity Software House, Topsham, ME).

\subsection{Immunofluorescence assay}

The cancer cells were grown on polylysine-coated coverslips, treated with $\mathbf{R u 2}$ $(0.30 \mu \mathrm{M})$ and Ru1 $(15.78 \mu \mathrm{M})$, these cells rinsed in phosphate-buffered saline, fixed in cold methanol for $20 \mathrm{~min}$, permeabilized for $10 \mathrm{~min}$ in $0.5 \%$ Triton $\mathrm{X}-100$ on ice, and blocked in 5\% BSA for $30 \mathrm{~min}$ at room temperature. The coverslips were incubated with rabbit monoclonal anti-H2A.X (Abcam) primary antibodies for 240 min at $25{ }^{\circ} \mathrm{C}$. The coverslips were washed and incubated with fluorescein conjugated 
goat anti-secondary antibodies (Alexa Fluor ${ }^{\circledR} 488$ Goat Anti- Rabbit IgG, green) for $30.0 \mathrm{~min}$. Finally, these cells stained with $0.1 \mathrm{mg} / \mathrm{mL}$ DAPI. Fluorescence images were visualized by LeicaTCS-SP5 confocal microscope (Germany, magnification $400 \times)$

\subsection{TRAP assay (TRAP-Silver Staining Assay)}

The telomerase extract was prepared from the cancer cells: a total of $5 \times 10^{6} \mathrm{Hep}-\mathrm{G} 2$ tumor cells untreated or treated with $\mathbf{R u} 2(0.30 \mu \mathrm{M})$ and $\mathbf{R u 1}(15.78 \mu \mathrm{M})$ were pelleted, and the cells were washed with $5 \mathrm{~mL}$ of PBS, scraped and lysed for $30 \mathrm{~min}$ on ice. Finally, the lysate was centrifuged at $13000 \mathrm{rpm}$ for $30 \mathrm{~min}$ at $4{ }^{\circ} \mathrm{C}$; the supernatant was collected and stored at $-80{ }^{\circ} \mathrm{C}$ before use. The TRAP assay was performed by following previously published procedures. Telomerase extract was prepared from SK-OV-3/DDP cells. A modified version of the TRAP assay was used. PCR was performed in a final $50 \mathrm{~mL}$ reaction volume composed of reaction mix (45 $\mathrm{mL})$ containing Tris- $\mathrm{HCl}(20 \mathrm{mM}, \mathrm{pH} 8.0)$, deoxynucleotide triphosphates (50 mM), $\mathrm{MgCl}_{2}(1.5 \mathrm{mM}), \mathrm{KCl}(63 \mathrm{mM})$, EGTA $(1 \mathrm{mM})$, Tween-20 (0.005\%), BSA (20 $\mathrm{mg} / \mathrm{mL}$ ), primer $\mathrm{H} 21 \mathrm{~T}$ (3.5 pmol; $\left.5^{\prime}-\mathrm{G}_{3}\left[\mathrm{~T}_{2} \mathrm{AG}_{3}\right]_{3}-3^{\prime}\right)$, primer $\mathrm{TS}$ (18 pmol; 5'-AATCCGTCGAGCAGAGTT-3'), primer Cxext $\quad(22.5 \quad$ pmol; 5'-GTGCCCTTACCCTTACCCTTACCCTAA-3'), primer $\quad$ NT $\quad(7.5$ pmol; 5'-ATCGCTTCTCGGCCTTTT-3'), TSNT internal control $(0.01$ amol; 5'-ATtCCGTCGAGCAGAGTtAAAAGGCCGAGAAGCGAT-3'), Taq DNA polymerase (2.5 U), and telomerase (100 $\mathrm{ng})$. Compounds or distilled water was added $(5 \mathrm{~mL})$. PCR was performed in an Eppendorf Master cycler equipped with a hot lid and incubated for $30 \mathrm{~min}$ at $30{ }^{\circ} \mathrm{C}$, followed by $92{ }^{\circ} \mathrm{C} 30 \mathrm{~s}, 52{ }^{\circ} \mathrm{C} 30 \mathrm{~s}$, and $72{ }^{\circ} \mathrm{C}$ $30 \mathrm{~s}$ for 30 cycles. After amplification, loading buffer $(8 \mathrm{~mL} ; 5 \times \mathrm{TBE}$ buffer, $0.2 \%$ bromophenol blue, and $0.2 \%$ xylene cyanol) was added to the reaction. An aliquot (15 
$\mathrm{mL})$ was loaded onto a nondenaturing acrylamide gel $(16 \% ; 19: 1)$ in $1 \times$ TBE buffer and resolved at $200 \mathrm{~V}$ for $1 \mathrm{~h}$. Gels were fixed and then stained with $\mathrm{AgNO}_{3}$.

\subsection{Western blotting}

Tumor cells harvested from each well of the culture plates were lysed in $150 \mu \mathrm{L}$ of extraction buffer consisting of $149 \mu \mathrm{L}$ of RIPA Lysis Buffer and $1 \mu \mathrm{L}$ PMSF (100 $\mathrm{mM}$ ). The suspension was centrifuged at $10000 \mathrm{rpm}$ at $4{ }^{\circ} \mathrm{C}$ for $10 \mathrm{~min}$, and the supernatant (10 $\mu \mathrm{L}$ for each sample) was loaded onto $10 \%$ polyacrylamide gel and then transferred to a microporous polyvinylidene difluoride (PVDF) membrane. Western blotting was performed using anti-c-myc, hTERT, and $\beta$-actin antibody and horseradish peroxidase-conjugated antimouse or antirabbit secondary antibody. Protein bands were visualized using chemiluminescence substrate.

\subsection{Acute Toxicity Studies}

Six-week old male and female KM mice (weight 20-22 g) were randomly divided into 3 groups $(n=6)$ and used to study the in vivo safety of Ru2. The highest solubility of Ru2 in solvent (5\% v/v DMSO/saline) was used as the solution, and a good practice volume $(0.6 \mathrm{~mL} / 20 \mathrm{~g})$ by intraperitoneal injection was used. Two groups of KM mice were treated with $\mathbf{R u} 2$ at dose $10.0 \mathrm{mg} / \mathrm{kg}$ every two day $(5 \% \mathrm{v} / \mathrm{v}$ $\mathrm{DMSO} / \mathrm{saline}$ ), respectively, and one group received the same volume of solvent and used as the control. The signs of toxicity were observed, and body weight was recorded daily.

\subsection{Anti-cancer activity toward NCI-H460 cancer xenograft in vivo}

The NCI-H460 cells were harvested and injected subcutaneously into the right flank of nude mice with $5 \times 10^{6}$ cells in $200 \mu \mathrm{L}$ of serum-free medium. When the xenograft tumor growth to the volume about $1000 \mathrm{~mm}^{3}$, the mice were killed and the tumor tissue were cut into about $1.5 \mathrm{~mm}^{3}$ small pieces, and then transplanted into the 
right flank of female nude mice, When tumors reach a volume of $80-190 \mathrm{~mm}^{3}$ on all mice, the mice were randomized into vehicle control and treatment groups ( $\mathrm{n}=6 /$ group), received the following treatments: (a) control, $5 \% \mathrm{v} / \mathrm{v} \mathrm{DMSO} / \mathrm{saline}$ vehicle, (b) Ru2 at dose $10.0 \mathrm{mg} / \mathrm{kg}$ every two day (5\% v/v DMSO/saline). The tumor volumes were determined every three days by measuring length $(l)$ and width $(w)$ and calculating volume, tumor volume and inhibition of tumor growth were calculated using formulas 1-3:

Tumor volume: $\mathrm{V}=\left(\mathrm{w}^{2} \times 1\right) / 2$

The tumor relative increment rate: $\mathrm{T} / \mathrm{C}(\%)=\mathrm{T}_{\mathrm{RTV}} / \mathrm{C}_{\mathrm{RTV}} \times 100 \%$

inhibition of tumor growth: $\operatorname{IR}(\%)=\left(\mathrm{W}_{\mathrm{c}}-\mathrm{W}_{\mathrm{t}}\right) / \mathrm{W}_{\mathrm{c}} \times 100 \%$

Where $\mathrm{w}$ and 1 mean the shorter and the longer diameter of the tumor respectively; $\mathrm{T}_{\mathrm{RTV}}$ and $\mathrm{C}_{\mathrm{RTV}}$ was the RTV of treated group and control group respectively. (RTV: relative tumor volume, $\left.\mathrm{RTV}=\mathrm{V}_{\mathrm{t}} / \mathrm{V}_{0}\right) ; \mathrm{W}_{\mathrm{t}}$ and $\mathrm{W}_{\mathrm{c}}$ mean the average tumor weight of complex-treated and vehicle controlled group respectively.

In addition, NCI-H460 xenograft mouse models were purchased from Beijing HFK Bioscience Co., Ltd (Beijing, China, approval No. SCXK 2014-004). The animal procedures were approved by the Institute of Radiation Medicine Chinese Academy of Medical Sciences (Tian Jin, China, approval No. SYXK 2014-0002). And all of the experimental procedures were carried out in accordance with the NIH Guidelines for the Care and Use of Laboratory Animals. Animal experiments were approved by the Animal Care and Use Committee of Institute of Radiation Medicine Chinese Academy of Medical Sciences.

\subsection{Statistical Analysis}

The experiments have been repeated from three to five times, and the results 
obtained are presented as means \pm standard deviation (SD). Significant changes were assesses by using Student's $t$ test for unpaired data, and $\mathrm{p}$ values of $<0.05$ were considered significant.

\subsection{Abbreviations}

SD, standard deviation; TBS, Tris-HCl buffer; MTT, 3-(4,5-dimethylthiazol-2-yl)-2,5-diphenyltetrazolium bromide; TGI, tumor growth inhibition; IR, tumor growth inhibition rate.

\section{- REFERENCES}

(1) Leung, K.-H.; He, H.-Z.; He, B.; Zhong, H.-J.; Lin, S.; Wang, Y.-T.; Ma, D.-L.; Leung, C.-H. Label-free luminescence switch-on detection of hepatitis C virus NS3 helicase activity using a G-quadruplex-selective probe. Chem. Sci. 2015, 6, 2166-2171.

(2) Cao, R.; Jia, J.-L.; Ma, X.-C.; Zhou, M.; Fei, H. Membrane localized iridium(III) complex induces endoplasmic reticulum stress and mitochondria-mediated apoptosis in human cancer cells. J. Med. Chem. 2013, 56, 3636-3644.

(3) Palanimuthu, D.; Shinde, S. V.; Somasundaram, K.; Samuelson, A. G. In vitro and in vivo anticancer activity of copper bis(thiosemicarbazone) complexes, J. Med. Chem. 2013, 56, $722-734$.

(4) Wilson, J. J.; Lippard, S. J. In vitro anticancer activity of cis-diammineplatinum(II) complexes with $\beta$-diketonate leaving group ligands. J. Med. Chem. 2012, 55, 5326-5336.

(5) Kassab, A. E.; Gedawy, E. M. Novel ciprofloxacin hybrids using biology oriented drug synthesis (BIODS) approach: Anticancer activity, effects on cell cycle profile, caspase-3 mediated apoptosis, topoisomerase II inhibition, and antibacterial activity. Eur. J. Med. Chem. 2018, 150, 403-418.

(6) Liu, F.; Gou, S.; Chen, F.; Fang, L.; Zhao, J. Study on antitumor platinum(II) complexes of chiral diamines with dicyclic species as steric hindrance. J. Med. Chem. 2015, 58, 6368-6377.

(7) Qin, Q.-P.; Wang, S.-L.; Tan, M.-X.; Wang, Z.-F.; Luo, D.-M.; Zou, B.-Q.; Liu, Y.-C.; Yao, P.-F.; Liang, H. Novel tacrine platinum(II) complexes display high anticancer activity via inhibition of telomerase activity, dysfunction of mitochondria, and activation of the p53 signaling 
pathway. Eur. J. Med. Chem. 2018, 158, 106-122.

(9) Sheldrick, G. M. SHELXTL-97, Program for refinement of crystal structures, University of Göttingen, Germany, 1997.

(9) Qian, C.; Wang, J.-Q.; Song, C.-L.; Wang, L.-L.; Ji, L.-N.; Chao, H. The induction of mitochondria-mediated apoptosis in cancer cells by ruthenium(II) asymmetric complexes. Metallomics 2013, 5, 844-854.

(10) Aird, R. E.; Cummings, J.; Ritchie, A. A.; Muir, M.; Morris, R. E.; Chen, H.; Sadler, P. J.; Jordrell, D. I. In vitro and in vivo activity and cross resistance profiles of novel ruthenium(II) organometallic arene complexes in human ovarian cancer. Br. J. Cancer 2002, 86, 1652-1657.

(11) Chen, Z.-F.; Qin, Q.-P.; Qin, J.-L.; Liu, Y.-C.; Huang, K.-B.; Li, Y.-L.; Meng, T.; Zhang, G.-H.; Peng, Y.; Luo, X.-J.; Liang, H. Stabilization of G-quadruplex DNA, inhibition of telomerase activity and tumor cell apoptosis of organoplatinum(II) complexes with oxoisoaporphine. J. Med. Chem. 2015, 58, 2159-2179. 